IZA DP No. 6457

Political Instability and Labor Market Institutions

Claudio Lucifora

Simone Moriconi

March 2012

Forschungsinstitut zur Zukunft der Arbeit Institute for the Study of Labor 


\title{
Political Instability and Labor Market Institutions
}

\author{
Claudio Lucifora \\ Università Cattolica \\ and IZA \\ Simone Moriconi \\ ITEMQ, Università Cattolica di Milano \\ and CREA, University of Luxembourg
}
Discussion Paper No. 6457
March 2012

\author{
IZA \\ P.O. Box 7240 \\ 53072 Bonn \\ Germany \\ Phone: +49-228-3894-0 \\ Fax: +49-228-3894-180 \\ E-mail: iza@iza.org
}

\begin{abstract}
Any opinions expressed here are those of the author(s) and not those of IZA. Research published in this series may include views on policy, but the institute itself takes no institutional policy positions.

The Institute for the Study of Labor (IZA) in Bonn is a local and virtual international research center and a place of communication between science, politics and business. IZA is an independent nonprofit organization supported by Deutsche Post Foundation. The center is associated with the University of Bonn and offers a stimulating research environment through its international network, workshops and conferences, data service, project support, research visits and doctoral program. IZA engages in (i) original and internationally competitive research in all fields of labor economics, (ii) development of policy concepts, and (iii) dissemination of research results and concepts to the interested public.
\end{abstract}

IZA Discussion Papers often represent preliminary work and are circulated to encourage discussion. Citation of such a paper should account for its provisional character. A revised version may be available directly from the author. 


\section{ABSTRACT}

\section{Political Instability and Labor Market Institutions ${ }^{*}$}

This paper investigates the relationship between political instability and labor market institutions. We develop a theoretical model in which some features of the political process, by reducing the future yields of policy interventions, induce an incumbent government to choose labor market institutions that create wage rents and divert resources from public good provision and social insurance. We test these predictions empirically using panel data for 21 OECD countries for the period 1985-2006. We find strong evidence that political turnover and political polarization - our measures of political instability - are associated with a more regulated labor market, lower unemployment benefit replacement rates, and a smaller tax wedge on labor. We show also that there are strong complementarities between different dimensions of political instability, and evaluate their impact on labour market institutions across countries.

JEL Classification: J64, J88, H11

Keywords: political instability, labor market institutions, unemployment

Corresponding author:

Claudio Lucifora

Department of Economics

Università Cattolica

1, L.go Gemelli

20123 Milano

Italy

E-mail: claudio.lucifora@unicatt.it

\footnotetext{
* We received useful comments and suggestions from Andrea Bassanini, Kristian Behrens, Michel Beine, Georges Bressons, Eve Caroli, Quentin David, Domenico Delli Gatti, Damien Gaumont, Etienne Lehmann, Michele Longo, Marco Lossani, Maurizio Motolese, Yasusada Murata, Yasuhiro Sato, Bruno van der Linden, David Wildasin and Skerdilajda Zanaj. Previous versions of this paper were presented at various International Conferences: 'Economic Integration, Trade, and Spatial Structure' (Nagoya University, Japan), $8^{\text {th }}$ Journées Louis-André Gérard-Varet (Marseille, France), 2009 Annual Conference of the European Association of Labour Economist (Tallin, Estonia) and in seminars at Kyoto University, Università Cattolica, Université de Paris 2, Université du Luxembourg and Université de Paris X. We are grateful to Andrea Bassanini and Romain Duval for providing the 'OECD Labour Market Institutions Data'. Access to World Bank political indicators data is also gratefully acknowledged. Part of this paper was completed when Claudio Lucifora was visiting the School of Economics at UNSW.
} 


\section{Introduction}

The recent financial crisis has brought unemployment back to the top of the policy agendas of most industrialized countries. While the effects of the crisis in terms of both GDP slowdown and unemployment rates were very different across countries, the existence of extensive regulation of product and labor markets has been considered to be one of the main drivers of poor economic performance and sluggish recovery. Barriers to competition and labour market institutions, by distorting economic agents' decision making, are often associated with lower income, slower growth and higher equilibrium unemployment (Blanchard and Wolfers [17], Griffith et al. [34], Botero et al. [18], Aghion et al. [3], Barro [13], Alesina et al. [6]). Institutions and regulations are the result of complex interactions among society's preferences, the vested interests of selected groups, and the political process used by policy makers to set the regulatory framework within which markets operate. In this context, a large literature shows that instability of the political process and friction in policy-making can yield a number of inefficient economic outcomes, such as public overspending, higher taxes, lower levels of private investment, and lower growth (Alesina and Perotti [8], Persson and Svensson [40], Svensson [45], Azzimonti [12], Cukierman et al. [25], Devereux and Wen $[27])^{1}$

In this paper, we investigate - theoretically and empirically - the relationship between some features of the political process and the design and implementation of labor market regulations. In the first part of the paper, we propose a theoretical model in which some structural features of the political system can affect the duration in office of an incumbent government, reducing the future yields of policy interventions (Svensson [45], Cukierman et al. [25], Devereux and Wen [27]). The main idea is that less stable political settings may result in an optimal choice to misallocate resources by introducing regulations that create wage rents but reduce public good provision and unemployment insurance. We assume that there are two parties (or political coalitions), which differ with respect to their preferences ('political polarization') over the composition - not level - of government spending, and when in power, decide on labor regulation, unemployment benefits, and fiscal policy. Labor regulation, however, takes time to be implemented since it influences the determination of rents

\footnotetext{
${ }^{1}$ Recognition of the role of the political process in determining market regulations and institutions lies behind many attempts by international organizations - such as the OECD Job Strategy, the EU Lisbon agenda, the World Bank's report on 'Understanding Regulation' and the more recent EU2020 Strategy urging governments to reform labor markets.
} 
and often faces strong opposition from social groups with vested interests. Therefore, it is designed in the first period but is implemented only in the second period, alongside fiscal policy. In this framework, the likelihood that a political shock occurring between the two periods may replace the incumbent government with a competitor ('political turnover'), has the effect of reducing the 'enforceability' of the chosen policy and inducing the incumbent government to divert resources from public good provision and social insurance. ${ }^{2}$ In other words, we argue that unstable and polarized political systems are more likely to be characterized by a negative externality, which, through higher labor market regulation, favors inefficient outcomes such as: wage rents, higher equilibrium unemployment, lower public good provision, and unemployment insurance.

In the second part of the paper, we test these predictions empirically using panel data for 21 OECD countries over the period 1985-2006, that include information on the political setting, labor market regulation, and several indicators of economic performance. We specify and estimate an empirical model to analyze whether the political setting can account for the observed differences in labor market institutions - such as labor regulations, unemployment benefit replacement ratios, and labor taxation - for selected OECD countries. In line with the theoretical model, we specify two complementary dimensions of political instability, political turnover, and polarization of preferences (Grofman and Van Roozendaal [35], Cukierman et al. [25]). These are measured combining the structural features of the political setting (e.g. constitutional procedures, aspects of the legislative organization), and characteristics of the political process in the legislature (e.g. cabinet attributes, and the ideological structure of party competition and cabinet composition). Labor market regulation refers to policies that affect workers' bargaining power and their ability to extract rents, which we proxy using a synthetic indicator of regulation in the areas of employment and collective relations law (e.g. union policies, bargaining structure, and employment protection legislation; see Griffith et al. [34]). Consistent with our theoretical model, we keep these regulations distinct from the set of institutions related to public finance and unemployment insurance, such as the tax wedge on labor and unemployment benefits replacement ratios. We find strong evidence that political turnover and polarization, proxied by our political indicators, are associated with

\footnotetext{
${ }^{2}$ This approach is justified by the existence of exogenous factors, e.g. related to electoral rules, structure of parliamentary representation, etc., which hinder the duration in office of any elected government (e.g. Høj et al. [37]; Fabrizio and Mody [31]). Hence, we depart from an approach that considers instability to be an endogenous outcome stemming from voter discontent, and hinders the probability of re-election of a government. Buti et al. [20] show that reformist governments are not penalized in re-elections if well-functioning financial markets bring forward future yields from structural reform, to the present.
} 
more regulated labor markets, lower unemployment benefit replacement rates, and a smaller tax wedge on labor. We show also that there are strong complementarities between the two dimensions of political instability, that is, the impact of political turnover on regulation and other labor market institutions is larger in more polarized political systems (and vice versa). The above results are shown to be robust to a number of extensions, such as the inclusion of alternative political indicators and different legal origin systems (Botero et al. [18]). We replicate the analysis estimating the model using instrumental variables to account for potential endogeneity between political instability and labor market institutions.

Our paper contributes to the literature in several ways. First, it analyzes the relationship between political instability and a number of institutional reforms whose benefits are expected in the future - such as public debt stabilization, privatization of public utilities, and protection of property rights (Svensson [45], Cukierman et al. [25], Devereux and Wen [27] and Alesina and Drazen [7]). In particular, Azzimonti [12], for a cross section of countries, excluding non-democracies, shows that greater polarization results in barriers to investment which are mitigated by the degree of political stability. Here, we focus on labor market institutions and show that political instability can explain why governments often take inefficient decisions with respect to labor regulations, or are reluctant to change them even in a context of high unemployment. This has some costs since it reduces the resources available for public good provision, redistribution, and social insurance. Second, many studies rely on data with high cross-country variability in relation to the enforcement of democratic institutions, to construct measures of political instability based on revolutions, coups, and assassinations, which capture phenomena such as xenophobia, anti-Semitism, social unrest, and ultra-nationalism (e.g. Alesina et al. [4], Svensson [45] and the survey in Carmignani [22]). In contrast, we focus on a panel of 21 OECD countries characterized by a more homogeneous set of institutions. We show that political instability - measured in terms of political turnover and polarization - can have an impact on economic performance even within countries characterized by democratic institutions (Dutt and Mitra [28]) ${ }^{3}$. In the conclusion to this paper, we assess the implications of political instability, via labor market institutions, on unemployment patterns across countries. In contrast to the literature on labor or product market institutions originating from long term processes and, hence, exogenous to economic outcomes (Bassanini and Duval [14] and Arpaia and Mourre [11], Griffith et al. [34]), we

\footnotetext{
${ }^{3}$ Similar approaches are adopted in Milesi et al. [38] and Aghion et al. [2]. These studies use samples of established democracies and construct measures of political instability that refer to electoral procedures, and the characteristics of parliamentary coalitions.
} 
show that institutions are the outcome of an endogenous process related to the political system and to frictions in policy-making decisions (Botero et al. [18], Pagano and Volpin [39], Saint Paul [42]). We show also that institutions are complementary, which may explain in part why changing the status-quo through reforms is so difficult. ${ }^{4}$

The paper is organized as follows. Section 2 presents the theoretical model. Section 3 describes the data and the empirical strategy. Section 4 presents the main results and discusses some implications for selected countries. We also provide some alternative specifications and a set of tests of the robustness of the empirical findings. Section 5 discusses the implications of political instability for unemployment and provides some concluding remarks.

\section{The model}

We describe a model with homogeneous workers that inelastically supply labor and face an employment probability that is decreasing in the cost of labor. Employed workers are paid a wage that is increasing in the amount of labor market regulation and unemployment benefits, and unemployed workers receive the unemployment benefit. Government's welfare is a Benthamite function of workers' expected income and utility from public good provision. In our baseline model, the government chooses labor regulation - unionization, bargaining structure, and employment protection norms- as well as the amount and composition of the public good financed through labor taxes. Government policy action spans two periods. Since implementation of labor market policy is sluggish relative to fiscal policy, for example, due to stronger opposition, length of social concertation, etc., labor regulation is designed in period 0 and implemented in period 1, while fiscal policy (public good and unemployment benefit) is designed and implemented rapidly in period 1.

There are two parties in the political arena. Each is equally representative of workers' interests but has different preferences for the composition (but not the level) of the public good. ${ }^{5}$ One party is elected at the beginning of period 0 , to be in office until the end

\footnotetext{
${ }^{4}$ Vindigni [47] and Brügemann [19], argue that institutions can be a source of rents, particularly in the presence of idiosyncratic uncertainty: labor market regulation, by altering the distribution of resources among different groups, creates opportunities to develop institutions explicitly designed to protect the rents of the group with political power.

${ }^{5}$ The two parties can be considered to be representative of different parts of society, characterized by different preferences for public good provision but the same identical preferences in relation to labor income. This assumption is reasonable when we consider that, in industrialized economies, the median voter is likely to be an employed worker and represented by any majority coalition, irrespective of ideological preferences. Similarly, trade unions represent a politically relevant socio-economic group, and lobby actively for their members' welfare. Several examples, from different countries, support this hypothesis. In Germany, France
} 
of period 1, allowing time to design and implement labor market and fiscal policy. Under perfect political stability, government will set labor taxes at a level that maximizes public good provision and offers workers full unemployment insurance. However, political instability can occur if there is a positive probability that a political shock between period 0 and period 1, will replace the incumbent government by its competitor. This form of political instability reduces the enforceability of the public policy preferred by the incumbent government, henceforth, its expected utility from public consumption. Since expected utility is the opportunity cost of income, political instability induces government to divert resources from public good provision to labor income. When government's main policy is related to labor regulation, workers' bargaining power increases and wage rents are created. A tax moderation effect minimizes the distortionary effect of labor taxation on tax revenues and employment. We extend our baseline model to the case where government policy is related to both labor regulation as well as the unemployment benefits replacement rate. In this case, the level of unemployment insurance is chosen according to the relative importance of employed workers (the 'insiders') in the government's objective function. Overall, political instability leads to an inefficient equilibrium where labor market regulation and unemployment benefits replacement rates are chosen so as to increase the expected income of workers whether employed or unemployed - but at the cost of lower levels of employment and public good provision (Cukierman et al. [25], Svensson [45], Azzimonti [12]).

\subsubsection{The private sector}

A mass of homogeneous workers inelastically supplies one unit of labor. We assume each worker faces an aggregate employment function:

$$
l(c) \in[0,1], \quad l_{c}^{\prime}<0, \quad l_{c c}^{\prime \prime}<0 .
$$

$l(c)$ can also be interpreted as the probability of the representative worker being employed at labor $\operatorname{costs} c=w+\tau$ where $w$ are workers' product wages and $\tau$ is the labor tax levied on each unit of labor employed. ${ }^{6}$ Assume that a wage formation function exists which determines

and Italy the implementation of laws that, at different points in time, have been passed to try to liberalize flexible employment contracts, has been delayed or the laws have been changed. In Europe more generally, most labor market reforms have been implemented in a two-tier system which protects the interests and political influence of incumbents (Saint Paul [42]).

${ }^{6}$ For expositional simplicity, from hereon we refer only to $l$. It can be considered the aggregate labor 
how unemployment benefits $(v)$ and labor market regulation $(\mu)$ affect wages (Saint-Paul $[42]):$

$$
w=W(\mu, v) \text { s.t. } \quad v \geq \bar{v}, \quad W(0, \bar{v})=\bar{v} \quad \text { and } \quad W_{j}^{\prime}>0, \text { where } j=\mu, v \text {. }
$$

The first condition in (2), guarantees that unemployment benefits never fall below the workers' reservation wage $\bar{v}$, thus workers do not have any incentive to exit the labor market. The second condition guarantees that in a perfectly competitive labor market (i.e. one characterized by $\mu=0$ and $v=\bar{v}$ ) all workers earn the reservation wage, regardless of employment status. The final condition implies that unemployment benefits and labor market regulation increase wages (by raising workers' outside options and rents). We can define workers' expected income in the case of employment and unemployment:

$$
E[I]=w l+v(1-l) \equiv v+(w-v) l .
$$

Equation (3) describes three effects of $\mu, v$ and $\tau$ on workers' expected income. Any policy that increases the unemployment benefits increases the outside option. ${ }^{7}$ Both labor market regulation and unemployment benefits increase wage rents via (2). Finally, any policy that increases labor costs has a negative impact on workers' expected income because it also increases workers' probability of being unemployed via (1).

\subsubsection{Government}

The welfare of the two political parties is defined over two time periods. In period 0 welfare is exogenous and determined by past policy decisions. In period 1 , the expected welfare is additively separable into workers' expected income and the utility from public good provision. These are determined by the policies implemented by the incumbent government, and dis-

demand in the economy which is derived from profit maximization by perfectly competitive firms. The assumption of concavity $l_{c c}^{\prime \prime}<0$ ensures that the elasticity of labor demand is increasing with labor costs i.e. $\epsilon_{c}^{\prime}>0$ which is a sufficient condition for the concavity of government's welfare function. This assumption is used frequently in oligopoly models and in the tax incidence literature (e.g. Stern [44]). It encompasses the idea that policies that increase the cost of labor have complementary effects on unemployment (Coe and Snower [24]) e.g. via adjustments at the intensive (i.e. via firms' optimal hiring policies) and the extensive (i.e. via the number of firms operating in the market) margins.

${ }^{7}$ Later, we discuss government's choice of level of unemployment insurance and specify the level of unemployment benefits as a function of government's choice of the replacement rate $\rho$. 
counted at a rate $\eta$. The parties present the same marginal utility from public consumption, which is higher than the marginal utility of income $(\delta>1)$ :

$$
E\left[V^{i}\right]=\bar{V}_{0}+\eta E\left[V_{1}^{i}\right] \text { where } E\left[V_{1}^{i}\right]=E[I]+\delta E\left[G^{i}\right] \quad \text { and } \quad i=a, b
$$

Parties $a$ and $b$ have different preferences regarding the composition of public good provision and exogenous probabilities $p$ and $1-p$ of being replaced in period 1 by their competitor in government. The expected utility from public consumption for party $i=a, b$ is given by:

$$
E\left[G^{i}\right]=(1-p) G_{a}^{i}+p G_{b}^{i} . \quad i=a, b
$$

where $G_{a}^{i}$ and $G_{b}^{i}$ respectively are the utility levels accruing to party $i=a, b$ when party $a$ and party $b$ implement their preferred public policy, weighted respectively by the probabilities $(1-p)$ and $p$ of being in office in period 1. The public policy of party $i=a, b$ is the desired composition of public expenditure, between the two available public goods $g_{1}$ and $g_{2}$. Party $a$ 's preferences are defined as follows (Cukierman et al. [25], Svensson [45]):

$$
G_{i}^{a}=\left(\frac{1}{\gamma(1-\gamma)}\right) \min \left[\gamma g_{1},(1-\gamma) g_{2}\right] . \quad i=a, b
$$

Preferences $G_{i}^{a}$ determine the utility accruing to party a from public good provision when party $i=a, b$ implements its preferred policy platform. $G_{i}^{b}$ is obtained symmetrically by replacing $1-\gamma$ to $\gamma$ in (6). The parameter $\gamma \in(1 / 2,1)$ denotes the polarization of party preferences: the closer $\gamma$ is to $1 / 2$, the more party a values balanced consumption of $g_{1}$ and $g_{2}$; values of $\gamma$ close to 1 , indicate that party $a$ values $g_{2}$ relatively more than $g_{1}$; the reverse applies to party $b$. In other words, the closer $\gamma$ is to 1 , the more distant (polarized) are the parties' preferences.

Finally, total government expenditure on public good provision $\left(z=g_{1}+g_{2}\right)$ and unemployment benefits is financed from labor taxes. Government's budget constraint is:

$$
z+v(1-l)=\tau l
$$


Notice that this framework departs from the traditional ideological distinction of a rightwing party in favor of public good provision and a left-wing party in favor of redistribution of labor income. Workers' expected income (3) is the same in the welfare functions of both parties; the only difference between parties is over the composition (not the level) of the public good.

We assume the following timing: in period 0 government designs its labor market policy. Since its implementation is slow relative to the implementation of fiscal policy, we assume it is implemented in period 1 while fiscal policy is implemented in the same period that it is designed in. We start by analyzing fiscal policy in period 1 and then proceed by backward induction to labor market policy in period 0 .

\section{$2.1 \quad$ Fiscal policy}

In period 1, labor market policy is given and the incumbent government chooses the fiscal policy that will maximize its welfare (4) subject to the budget constraint (7). Assume without loss of generality that party $a$ is in office; given the structure of preferences (6), then the first order conditions of the maximization problem in period 1 are ( and see Appendix A for details):

$$
\begin{aligned}
& g_{1 a}=(1-\gamma) z ; \quad g_{2 a}=\gamma z . \\
& \delta l=-[w-v+\delta(\tau+v)] l_{c}^{\prime}
\end{aligned}
$$

Equation (8) describes the optimal public policy for a type $a$ government, that is, its preferred composition $\left(g_{1 a}, g_{2 a}\right)$. The optimal tax rule $(9)$ sets the labor tax at the level that equates to its marginal benefit in terms of higher public consumption (left side of equation (9)) to its marginal cost in terms of foregone employment (thus a lower tax base and higher expenditure for unemployment benefits; on the right side of (9)).

Equation (9) defines the first period equilibrium labor tax as an implicit function of the labor market policy, that is, $T(\mu, v)$. It holds that (proof in Appendix A):

Lemma: An equilibrium level of the labor tax exists $\tau^{*}=T(\mu, v)$ such that:

(i) $T(0, \bar{v})=\tau^{\max }$; 
(ii) there exist a pair $\widetilde{\mu}>0$ and $\widetilde{v}>\bar{v}$ s.t. $T(\mu, v)<\tau^{\max }$, for any $\mu>\widetilde{\mu}$ and $v>\widetilde{v}$;

(iii) if $T(\mu, v)<\tau^{\max }$, then $T_{j}^{\prime}<0$ with $j=\mu, v$.

The optimal tax rule (9) implies that when $\mu=0$ and $v=\bar{v}$, government sets the optimal labor $\operatorname{tax} \tau^{\max }$, as in (i) above. Because the optimal labor tax creates unemployment, part of the tax revenue is used to distribute unemployment benefits. ${ }^{8}$ However, any $\mu>0$ and $v>\bar{v}$, increase the employment penalty of the labor tax and induce government to pursue a policy of 'tax moderation'. The government then sets $\tau^{*}<\tau^{\max }$, as in (ii) above and responds to any labor market policy increase by cutting the labor tax, as in (iii) above. ${ }^{9}$ The tax moderation policy alleviates unemployment and increases the share of workers that benefit from wage rents.

\subsection{Labor market regulation}

We assume, without loss of generality, that party $a$ is in office in period 0 and designs the labor market policy. Party a knows that with probability $1-p$ it will enjoy its preferred public policy but with probability $p$ it will be replaced in office by party $b$, which will implement its own preferred public policy. We obtain the expected welfare of party $a$ in period 0 by plugging the corresponding utilities from public consumption into equation (5) (see Appendix A for the analytical details):

$$
E\left[V^{a}\right]=\bar{V}_{0}+\eta[v+(w-v) l+\omega(\delta, p, \gamma) z] \quad \text { where } \quad \omega(\delta, p, \gamma)=\delta \phi(p, \gamma)
$$

$\omega(\delta, p, \gamma)$ denotes the expected marginal utility from public consumption of party $a$. This depends on the marginal utility $\delta$ from (the level of) public good provision and on the degree of enforceability of party $a$ 's public policy $\phi(p, \gamma) \cdot{ }^{10}$ The following holds:

\footnotetext{
${ }^{8}$ The generality of our approach does not exclude a priori the possibility that government's optimal choice is to impose a labor subsidy i.e. a negative labor tax. However, it can be argued that government optimally chooses a positive labor tax when $\delta$ is high enough.

${ }^{9}$ In fact, under the assumption $l_{c c}^{\prime \prime}<0$, a labor market policy $j=\mu, v$ increases the elasticity of the demand for labor with respect to labor costs, and thus the size of the employment penalty of the labor tax.

${ }^{10}$ The degree of enforceability can be interpreted as the probability that party $a$ will see its public policy implemented. Persson and Svensson [40] interpret $\phi(p, \gamma)$ as a measure of the time inconsistency of public policy, meaning that the incumbent government in period 0 (i.e. party $a$ ) cannot commit to its announced policy due to an exogenous probability of being replaced by a government that will implement a different policy.
} 


$$
\begin{aligned}
& \text { (i) } \lim _{p \rightarrow 0} \omega(\delta, p, \gamma)=\lim _{\gamma \rightarrow \frac{1}{2}} \omega(\delta, p, \gamma)=\delta \\
& \text { (ii) } \omega_{p}^{\prime}<0 ; \quad \omega_{\gamma}^{\prime}<0 \\
& \text { (iii) } \lim _{\substack{\gamma \rightarrow 1 \\
p \rightarrow 1}} \omega(\delta, p, \gamma)=0 .
\end{aligned}
$$

When party $a$ is certain to be in office in the next period (no matter the degree of preference polarization) or when its preferences are fully consistent with those of party $b$ (independent of the probability of political turnover), as in (i) above, its public policy will be fully enforceable $(\operatorname{as} \phi(0, \gamma)=\phi(p, 1 / 2)=1)$. This allows $a$ to expect the highest possible utility from public consumption (i.e. $\omega(\delta, 0, \gamma)=\omega(\delta, p, 1 / 2)=\delta$ ). However, political instability, that is, the probability that government $a$ will be replaced in period 1 by government $b$ which will implement a different public policy, hinders the enforceability of its public policy, as in (ii) above. This, in turn, reduces its expected utility from public consumption. In the limit, as in (iii) above, when it is certain to be replaced in period 1 by party $b$ which is characterized by opposite preferences, party $a$ has no chance to see its public policy enforced (i.e. $\phi(1,1)=0$ ) and does not expect any utility gain from public good provision $(\operatorname{as} \omega(\delta, 1,1)=0)$.

We now turn to the optimal labor market policy. We assume that $v=\bar{v}$ so $\mu$ is the only instrument available for labor market policy (we relax this assumption in the next section). ${ }^{11}$ Party $a$ then chooses $\mu$ to maximize (10) subject to the incentive compatibility constraint $T(\mu, v)$. The first order condition is (see Appendix B for details):

$$
V_{\mu}^{\prime}=\underbrace{\frac{(w-\bar{v})(\delta-1) l_{c}^{\prime}}{\delta}}_{\text {unemployment }(<0)}+\underbrace{[1-\phi(p, \gamma)] \frac{(w-\bar{v})}{w_{\mu}^{\prime}} T_{\mu}^{\prime} l_{c}^{\prime}}_{\text {tax moderation }(>0 \text { if } \phi<1)}+\underbrace{[\omega(\phi, p, \gamma)-1]\left(\tau^{*}+\bar{v}\right) l_{c}^{\prime}}_{\text {social expenditure }(>0 \text { if } \omega<1)}
$$

Equation (12) describes the incentives that guide the optimal design of labor market policy. Labor market regulation produces three effects on social welfare. The first is a direct

\footnotetext{
${ }^{11}$ This would be the case if the government in period 0 were myopic about the impact of political instability on unemployment and wages in period 1. A short-sighted government will simply set unemployment benefits equal to wages in period 0 , believing that this level will provide workers with full unemployment insurance. From the government's perspective, wages in period 0 will be exogenous since they are a legacy of past policies.
} 
impact of unemployment on welfare via lower wage rents. The second is a tax moderation effect because government reacts to any increase in labor costs in period 0 by cutting the labor tax. The third is an indirect impact of unemployment on welfare via the increase in social expenditure on unemployment benefits. The unemployment effect is always negative while the signs of the tax moderation and social expenditure effects are ambiguous a priori. If government's public policy is fully enforceable (i.e. $\phi=1$ ), government has no incentive to trade off public good provision against wage rents and the tax moderation effect is equal to zero. Moreover, any diversion of tax revenue away from public good provision will have a negative impact on welfare (as $\omega=\delta>1$ ) and the social expenditure effect will be negative. Overall, labor market regulation has a negative impact on welfare and government optimally chooses the corner solution $\mu^{*}=0$.

However, when political instability hinders the enforceability of government's public policy (i.e. $\phi<1$ ), then in period 0 government will trade off its (uncertain) implementation against (certain) wage rents, that is, the tax moderation effect will be positive. When $\phi$ is low enough (i.e. such that $\omega<1$ ), government will divert tax revenues from public good provision to social expenditure, that is, the social expenditure effect will be positive. When the positive tax moderation effect and social expenditure effect balance the negative unemployment effect, the first order condition $V_{\mu}^{\prime}=0$ allows an interior solution and government chooses an optimal amount of labor market regulation $\mu^{*}>0$. This can be expressed as an implicit function of political instability, that is, $\mu^{*}=M(p, \gamma)$, which leads to the following (see formal derivation and proof in Appendix A): ${ }^{12}$

Proposition 1: An equilibrium level of labor market regulation exists $\mu^{*}=M(p, \gamma)$ such that:

(i) $M(0, \gamma)=M(p, 1 / 2)=0$;

(ii) there exist a pair $\bar{p}<1$ and $\bar{\gamma}<1$ s.t. $M(p, \gamma)>0$ for any $p>\bar{p}$ and $\gamma>\bar{\gamma}$;

(iii) if $M(p, \gamma)>0$, then $M_{k}^{\prime}>0$ with $k=p, \gamma$.

With perfect political stability, the corner solution, as in (i) above, corresponds to a first best equilibrium with a perfectly competitive labor market (as $w=\bar{v}$ ). However, with

\footnotetext{
${ }^{12} \phi<1 / \delta$ is then a sufficient condition for (12) to allow an interior solution. We assume also that the second order conditions are satisfied, which requires some assumptions about the third order derivatives of $l(c)$ as is generally the case in optimal taxation problems.
} 
a sufficient degree of political instability, the low future yields from public policy induce government to divert resources from public good provision to labor income by setting a positive level of regulation, as in (ii) above. This corresponds to a second best equilibrium with higher unemployment and wage rents (as $w-\bar{v}>0$ ). The higher the level of political instability, the higher will be the optimal amount of labor market regulation, as in (iii) above.

From the Lemma and Proposition 1 it follows that there is a relationship between political instability and equilibrium labor taxes. By inducing a higher wage bill, political instability forces government to alleviate the tax burden and thus to reduce the cost of labor and also reduce employment losses. Then we have the following:

Proposition 2: Political instability induces an equilibrium with lower labor taxes as $T_{k}^{\prime}=$ $T_{\mu}^{\prime} M_{k}^{\prime}<0$ where $k=p, \gamma$.

In this section, the restrictive assumption of exogenous unemployment benefits allowed us to focus on the relationship between political instability and labor market regulation but prevented analysis of another important dimension of government's labor market policy, that is, the choice of level of unemployment insurance. In the next section, we relax this assumption and endogenize the choice of the unemployment benefits replacement rate. This allows some theoretical predictions regarding the relationship between political instability and the degree of unemployment insurance.

\subsection{Unemployment insurance}

The analysis so far has assumed that unemployment benefits are set exogenously at the workers' reservation wage. However, this ignores another important dimension of labor market policy, that is, the choice of level of workers' insurance against unemployment. Below, we present an extension of the baseline model where government optimally chooses the unemployment benefits replacement rate $(\rho)$-that is, unemployment benefits relative to wages. We impose $v=\rho w$ and can rewrite the wage formation function (2) in relation to $\mu$ and $\rho:^{13}$

\footnotetext{
${ }^{13}$ Equation (13) is the exact counterpart of $w-W(\mu, \rho w)=0$ which is obtained by plugging $v=\rho w$ into (2). Note that, since unemployment benefits are now fully indexed to wages, in moving from (2) to (13) we need to account for the indirect impact of $\rho$ and $\mu$ on $v$. We impose $W_{v}^{\prime}<1 / \rho$ since this guarantees $\Psi_{\mu}^{\prime}>0$ and $\Psi_{\rho}^{\prime}>0$. Note also that, from (13) the replacement rate consistent with $v=\bar{v}$ is equal to 1 in a perfectly
} 


$$
w=\Psi(\mu, \rho) \text { s.t. } \quad \rho w \geq \bar{v}, \quad \text { and } \Psi_{j}^{\prime}>0, \text { where } j=\mu, \rho \text {. }
$$

We introduce a trade off in the choice of $\mu$ and $\rho$, in the objective function of government in period $0 .{ }^{14}$ In particular, we assume that government in period 0 internalizes the employment objective of those already employed at that time, the so-called 'insiders' (Blanchard and Summers [16]):

$$
l_{I}=\alpha(p, \gamma) l_{0}+[1-\alpha(p, \gamma)] l, \text { where } 0<\alpha<1 \text { and } \alpha_{k}^{\prime}>0, \quad k=p, \gamma
$$

$\alpha$ in (14) is the measure of the self-interest of 'insiders'. We assume the following holds:

(i) $\lim _{p \rightarrow 0} \alpha(p, \gamma)=\lim _{\gamma \rightarrow \frac{1}{2}} \alpha(p, \gamma)=0$

(ii) $\alpha_{p}^{\prime}>0 ; \quad \alpha_{\gamma}^{\prime}>0$

(iii) $\lim _{\substack{\gamma \rightarrow 1 \\ p \rightarrow 1}} \alpha(p, \gamma)=1$.

With perfect political stability, as in (i) above, government implements a perfectly competitive labor market, thus insiders do not have any interest in maintaining current membership, that is, $\alpha(0, \gamma)=\alpha(p, 1 / 2)=0$ and $l_{I}=l$. However, with political instability government creates wage rents shifting insiders' preferences towards maintaining current membership, as in (ii) above. At the limit, as in (iii) above, when government is certain to be replaced in period 1 by its competitor (e.g. characterized by opposite preferences), wage rents are maximized and insiders are concerned only about their employment status, that is, $\alpha(1,1)=1$ and $l_{I}=l_{0}$.

Replace $l$ with $l_{I}$ and plug $v=\rho w$ in (10) to obtain the welfare function of government in period 0:

competitive labor market (i.e. when $w=\bar{v}$ ) and is decreasing in the size of labor market distortions when $\bar{v} / w<1$.

${ }^{14}$ Since the marginal utility of income is always higher than the expected utility from public good provision, in the absence of any trade-off between $\mu$ and $\rho$, government in period 0 sets $\mu^{*}>0$ and $\rho^{*}=1$, i.e. an equilibrium where workers enjoy full unemployment insurance regardless of the degree of political instability. 


$$
E\left[V_{I}^{a}\right]=\bar{V}_{0}+\eta\left[\rho w+(w-\rho w) l_{I}+\omega(\delta, p, \gamma) z\right]
$$

The equilibrium in period 0 is a combination of $\mu$ and $\rho$ which maximizes (16) subject to the incentive compatibility constraint given by the optimal tax rule $\tau^{*} \cdot{ }^{15}$ Note that in the benchmark case of perfect political stability, government at the equilibrium designs a perfectly competitive labor market (with full unemployment insurance), that is, $\mu^{*}=0$, $\rho^{*}=1$, thus $w^{*}=v^{*}=\bar{v}$. In the presence of political instability, since $\mu$ influences workers' expected income only via wages, while $\rho$ affects expected income both via wages and the degree of social insurance, government uses $\mu$ to target wages and sets $\rho$ based solely on insurance considerations. At the equilibrium level of labor market regulation $\mu^{*}$, when $\rho$ is set exclusively to maximize unemployment insurance, its impact on welfare is described by the following (see Appendix A for details):

$$
\left.V_{\rho}^{\prime}\right|_{\mu^{*}}=\underbrace{-\frac{\alpha\left(l_{o}-L\right)}{1-\rho}}_{\text {insiders' }^{\prime} \text { rents }(<0 \text { if }}+\underbrace{[1-\phi(p, \gamma)-\alpha(p, \gamma)] \hat{T}_{\rho}^{\prime} l_{c}^{\prime}}_{\left.l_{0}>L\right)}-\underbrace{(\omega(\phi, p, \gamma)-1) \frac{(1-L)}{1-\rho}}_{\text {tax moderation }(>0 \text { if } 1-\alpha>\phi)} .
$$

Equation (17) shows that $\rho$ has three effects on aggregate welfare. The first term shows a direct impact of insiders on welfare via lower wage rents. The second term describes a tax moderation effect because government in period 1 reacts to any increase in social expenditure in period 0 , by cutting the labor tax. The third term describes the impact on welfare of increased social expenditure on unemployment benefits. The insiders' rent effect is negative provided that insiders are under-exposed to unemployment, that is, $l_{o}>L$. The tax moderation effect is positive provided that the government's interest in outsiders is stronger than its public policy preferences (i.e. $1-\alpha>\phi$ ). Finally, the social expenditure effect is positive when $\phi$ is such that $\omega<1$ since it is optimal for government to divert tax revenues from public good provision to social expenditure. Since the negative effect of unemployment insurance on insiders' rents tends to balance the positive tax moderation and social

\footnotetext{
${ }^{15}$ Since government's objective in period 1 is still given by (4), equation (16) introduces a further asymmetry between labor market and fiscal policy, which can still be justified in relation to the different composition of their cabinets or the amount of social concertation needed over labor market and fiscal policy.
} 
expenditure effects, the first order condition $\left.V_{\rho}^{\prime}\right|_{\mu^{*}}=0$ admits an interior solution such that government optimally chooses an equilibrium with under-insurance, that is, $0<\rho^{*}<1$. $^{16}$ We have the following proposition (formal derivation and proof are presented in Appendix A):

Proposition 3: In the presence of political instability, an equilibrium level of the replacement rate exists $\rho^{*}=\Upsilon(p, \gamma)$ such that $\Upsilon_{k}^{\prime} \lesseqgtr 0$. In particular it holds $\Upsilon_{k}^{\prime} \leq 0$ if $\frac{\alpha_{k}^{\prime}}{\Theta \phi_{k}^{\prime}} \geq 1$ with $\Theta<0$.

Proposition 3 states that the impact of political instability on unemployment insurance at the equilibrium depends on a change in government's preferences for insiders (measured by $\alpha_{k}^{\prime}$ ) relative to labor income (measured by $\Theta \phi_{k}^{\prime}$ ). Political instability induces a lower replacement rate in the economy if it shifts government's preferences towards labor market insiders.

Overall, our results provide a clear picture of the impact of political instability on labor market institutions. Political instability shifts government's preferences from public good provision and labor taxation to labor income. In particular, if government's preferences tend to concentrate on labor market insiders, then insiders enjoy higher rents, resulting in lower unemployment benefits replacement rates.

\section{Data and empirical strategy}

The main empirical prediction of the theoretical model is that the instability of the political system $(\phi(p, \gamma)$, that is, political turnover and political polarization), via the government's labor market and fiscal policy, influences labor regulation, social insurance and redistribution. We test these hypotheses specifying and estimating a three equation system where degree of labor market regulation $(\mu)$, labor tax $(\tau)$ and unemployment benefits replacement ratios $(\rho)$ depend on a number of political instability indicators:

\footnotetext{
${ }^{16}$ Conditions $0<\phi<1-\alpha$ and $\delta>1 / \phi$ are sufficient for the first order condition (17) to admit an interior solution. Also in this case we assume that the second order conditions of government's maximization problem are satisfied.
} 


$$
\begin{aligned}
& \mu_{i t}=a_{1}^{\prime} \phi_{i t}+\mathbf{X}_{i t}^{\prime} \mathbf{l}+\alpha_{i}+\lambda_{t}+\epsilon_{i t} \\
& \tau_{i t}=a_{2}^{\prime} \phi_{i t}+\mathbf{X}_{i t}^{\prime} \mathbf{m}+\alpha_{i}+\lambda_{t}+\chi_{i t} \\
& \rho_{i t}=a_{3}^{\prime} \phi_{i t}+\mathbf{X}_{i t}^{\prime} \mathbf{n}+\alpha_{i}+\lambda_{t}+\nu_{i t} .
\end{aligned}
$$

Each equation in model (18) is specified as a function of the political instability in country $i$ at time $t$. We include a vector $\mathbf{X}_{i t}$ of controls for specific country characteristics or economic shocks in country $i$ at time $t$, and country and time fixed effects $\left(\alpha_{i}, \lambda_{t}\right)$ to control for time invariant country specific features and common time shocks. Positive (negative) coefficients of $\phi$ indicate that an increase in political instability is associated with a higher (lower) level of $\mu_{i t}, \tau_{i t}$ and $\rho_{i t}$. In particular, a mechanism consistent with our theoretical priors could be described by $a_{1}>0, a_{2}<0$ while the impact on the replacement rate is a priori ambiguous, that is, $a_{3} \lessgtr 0$.

\subsection{Variables}

We assembled a unique dataset that combines information from various data sources on political systems, labor market institutions, and economic performance for 21 OECD countries ${ }^{17}$ for the period 1985-2006. The focus on OECD countries conveys the idea that the implementation of labor market regulations requires a degree of enforcement of labor standards and government competences which occur only in well-established democracies, thus we exclude dictatorships and young democracies, which generally are characterized by weaker adoption of these standards.

We measure political instability as a feature of both the structural characteristics of the political setting and the stability within the legislature, using data from the World Bank Database of Political Institutions (DPI) (Beck et al. [15]). In line with the empirical specification of the institutional equations outlined in model (18), we construct two synthetic indicators, Polturn and Polpolar, to proxy for political turnover and polarization of political preferences. In the first case, we exploit the idea that the adoption of a proportional (or hybrid majoritarian) system, the presence of closed lists, the absence of a 'winner-takes-all'

\footnotetext{
${ }^{17}$ The 21 countries are: Australia, Austria, Belgium, Canada, Denmark, Finland, France, Germany, Greece, Ireland, Italy, Japan, Netherlands, Norway, New Zealand, Portugal, Spain, Sweden, Switzerland, United Kingdom and the United States.
} 
voting system, the incumbency of a minimal-winning (or even minority) government, and a number of veto players dropping out of government, signal a high propensity for government to terminate in any period (and before the end of the legislative period). These features determine higher frictions and low enforceability in policy-making decisions (Diermeier and Stevenson [26], Alesina et al. [5]). In the second case, we assume that a high ideological distance, and high fractionalization and dispersion of government and opposition ${ }^{18}$ may give a voice to minority ideological and possibly extremist positions, enhance political unrest and polarization in parliament with similarly detrimental effects on the enforceability of government's policy (Anesi and De Donder [9], Tsebelis and Chang [46]).

In practice, we use principal component analysis (PCA) to extract from the multiple dimensions described above, two synthetic indicators capturing the main features of political turnover (Polturn) and polarization (Polpolar) (details in Appendix B). Both indicators are standardized to have a zero mean and unit standard deviation. ${ }^{19}$ This approach has two important advantages. First, the complexity of a political system is captured by the multidimensional indicator which incorporates political attributes that have been shown to affect the stability of the political process. While the chosen variables are necessarily a selected set of the relevant features, the summary indicators do a good job at replicating the main political changes occurring in the sample period. Second, our summary indicators measure political instability on the basis of structural features without the need to rely on actual changes in the executive. This reduces concerns regarding the potential endogeneity of political and economic outcomes (see also Hibbs [36]). ${ }^{20}$ Throughout the analysis we check the robustness of the summary indicators against alternative specifications based on the degree of enforcement of democratic institutions and the country's legal origin. We also condition on some additional measures that may play a confounding role, such as government's ideological orientation, strength of the political parties, phases of the legislature. For

\footnotetext{
${ }^{18}$ Fractionalization and dispersion are complementary measures of parliamentary fragmentation; the former measures the effective number of the parties in a coalition; the latter measures the level of 'competition' (share of seats) among parties within the same coalition (see Beck et al. [15] for details).

${ }^{19}$ Political indicators are standardized as follows: $X_{i, t}^{h}=\frac{\left(X_{i, t}^{h}-\bar{X}^{h}\right)}{\sigma_{h}}$ where $X_{i, t}^{h}$ is the level of the political indicator $h$ in country $i$ at time $t, \bar{X}^{h}$ and $\sigma_{h}$, respectively, are the mean and standard deviation of the political indicator $h$ in the sample (i.e. in the average OECD country).

${ }^{20}$ The construction of an aggregate indicator based on the maximum variance of the individual variables simplifies both the estimation procedures and the interpretation of results. Reliance on single indicators would be unfeasible for the purposes of the present analysis. Note also that our approach differs from approaches in the literature that use a single indicator for the 'propensity' for political change estimated by probit regressions, where actual government changes are regressed against the indicators of socio-political unrest, i.e. events of mass violence, civil war, and political disorders (e.g. Cukierman et al. [25],Svensson [45]). See also Alesina and Perotti [8]for a discussion of these issues.
} 
expositional convenience, we use also an overall indicator of political instability (Polinst) obtained by simply summing the two indicators described above.

The second set of variables used in the empirical analysis, which are drawn from multiple OECD sources, describe the different labor market institutions. The labor market regulation indicator $(\mathrm{Lmr})$ is constructed as the unweighted sum of the selected variables, namely procedures regulating the dismissals of regular workers, (lack of) corporatist policies (e.g. social pacts, income policies, etc.), and trade union powers (OECD Labour Market Institutions Database, see Bassanini and Duval [14], Griffith et al. [34]). ${ }^{21}$ The labor tax indicator is measured as the marginal effective tax rate on labor (Ltax) -that is, labor taxation as a percentage of labor costs (OECD National Accounts and Revenue Statistics, see Carey and Rabesona [21]). The average unemployment benefits replacement ratio measure (Arr) is computed as the average of gross replacement rates across various earnings levels, family situations, and durations of unemployment (OECD Benefits and Wages Database). Other control variables include two dummies for being a member of the European Union $(E U)$ and a member of the European Monetary Union (Euro), and an indicator for occurrence of an economic crisis (Crisis). See Appendix B for more details on the definition of the variables used in the empirical analysis.

\subsection{Descriptive statistics}

To get an idea of how well our political indicators describe the patterns of political instability across countries, Figure 1 plots the median values of Polturn and Polpolar by country. We report the overall sample medians (dashed horizontal and vertical lines) that partition the graph into four quadrants, according to the political turnover and polarization dimensions. Each quadrant corresponds broadly to an alternative political setting. The bottom-left quadrant includes countries with a stable political setting. These are mainly Anglo-Saxon countries characterized by a low probability of government turnover - due to the presence of presidentialist systems, majoritarian electoral rules, and oppositions with little veto power. They present low levels of political polarization in parliament due to bi-partist voting systems which reduce political dispersion and fractionalization, even when the ideological distance

\footnotetext{
${ }^{21}$ The individual measures are standardized to have zero mean and unit standard deviation and then added together (Duval [29]). Our theoretical priors indicate that variables influencing workers' bargaining power should be kept distinct from those related to the set of incentives and social insurance, such as labor taxation and unemployment benefits. An alternative approach is described in Botero et al. [18] who include social security laws in their index of labor market regulation.
} 
between the majority and the opposition is large.

[Figure 1 here]

The upper-right quadrant includes countries with unstable political settings, mostly Nordic and Continental EU countries which have a high probability of political turnover based mainly on their pure proportional representation systems and high incidence of veto players in parliament, and high levels of political polarization due to substantial multipartism which enhances the degree of political polarization even in the presence of a small ideological distance between majority and opposition. Countries are mainly distributed between the bottom-left and upper-right quadrants suggesting that the two measures of political instability are positively correlated. ${ }^{22}$

[Figure 2 here]

Figure 2 plots the synthetic index of political instability Polinst against the set of our institutional variables. To account for (time invariant) unobserved factors which may be correlated with both the political and institutional settings, for example, the characteristics of the welfare state and legal origins, we take each variable in first difference between the 2004-2006 and the averages for the 1985-1987 sub period. Consistent with our theoretical priors, changes in political instability are positively correlated with changes in labor market regulation, and negatively correlated with changes in labor taxation over the sample period. Changes in political instability are negatively correlated with changes in the unemployment benefits replacement rates.

Countries that experienced shocks which led to increased political stability in the period 1985-2006 (Italy, Japan, Portugal, France, Switzerland, the US), generally show a reduced labor market regulatory setting, an increase in the tax rate on labor (particularly Italy and Portugal) and a rise in the (average) unemployment benefits replacement rate. The converse is true for countries that experienced increased political instability (e.g. New Zealand, Norway, Belgium and Netherlands) which introduced (sometimes pervasive) labor market regulations, and reduced labor taxes and unemployment benefits replacement rates. To illustrate our arguments we start comparing two countries characterized by similar income levels but with different political systems and labor market settings: New Zealand and Portugal

\footnotetext{
${ }^{22}$ There are some exceptions: e.g. Switzerland has high level of political polarization but relatively low political turnover due to its multi-party parliamentary system and large ideological distance between majority and opposition in a mostly majoritarian voting rule context; Portugal and Ireland have high levels of political turnover but low levels of political polarization due to proportional systems with closed lists which concede some veto power to the opposition in the presence of a substantial bi-partism.
} 
(Botero et al. [18]). At the beginning of the 1980s, New Zealand was a parliamentary democracy based on a winner-takes-all voting system and a labor market with low employment protection and a highly corporatist system of collective bargaining which dampened union wage pressures. In the same period, Portugal was a young parliamentary democracy with a constitution that strictly regulated several aspects of employment protection and collective relations laws. These countries experienced completely different political developments in the course of the next three decades. New Zealand experienced a big political shock after the binding referendum in 1993 which paved the way to the electoral reform and a switch from a majoritarian to a proportional electoral system. This reform ensured higher representation of smaller parties in its parliament but prevented the formation of stable coalitions around shared policy platforms. ${ }^{23}$ On the policy side, starting in the early 1990s, successive New Zealand governments introduced regulations that increased workers' bargaining power (i.e. they moved towards a fully decentralized and uncoordinated system of collective bargaining, increased labor protection, and introduced a role for state arbitration courts in setting wages; Castels and Mitchell [23]), and reformed the welfare system considerably, reducing both taxation and unemployment benefits (Freeman [32]). The young Portuguese democracy experienced substantial political stabilization and a revision of its Constitution during the sample period. ${ }^{24}$ This process favored the election of stable, centre-left, progressist government coalitions, able to undertake political reforms which eroded the constitutional rights guaranteed to employed workers and unions while reinforcing economic support of the welfare state and redistribution (Abreu and David [1]).

While New Zealand and Portugal can be considered extreme cases of radical change to the political setting and labor market institutions, the experience of several other countries, such as the UK, France, Italy, Germany, Netherland, Denmark and Spain, provides comparable evidence in terms of reforms in the labor market regulatory setting. In countries characterized by significant political instability over the period considered, such as Belgium, labor market reforms are on hold.

\footnotetext{
${ }^{23}$ The process was driven mainly by increasing political unrest during the 1980 s, Labor lost two consecutive elections despite winning more votes overall than the National Party. Following the switch to proportional representation, neither of the two main parties (National or Labor) has had a majority in parliament and they have been forced to form coalitions and rely on external support from minor parties to pass legislation.

${ }^{24}$ The first revision in 1982 placed the provisionary military government established after the 1976 revolution under strict civilian control. Further moves towards a stable political setting included accession to the European Union in 1986, and successive constitutional revisions which paved the way to the 1995 parliamentary election.
} 


\section{Results}

Table 1 presents the results for different specifications of the institutional equations outlined in model (18). All equations are estimated using ordinary least square (OLS) on the pooled sample, and include a number of control variables, for example, dummies for European Union and European Monetary Union, and for economic crisis, plus country and time fixed effects. Coefficients of the political indicators are always statistically significant at the conventional levels. Since the indicators of political instability vary across countries and over time, identification of their effect on labor market institutions is not affected by other sources of cross country variation.

[Table 1 here]

Consistent with our theoretical priors, the results in columns [1] and [2] indicate that a marginal increase in the overall Polinst indicator implies a 0.33 standard deviation increase in $L m r$ and a -0.92 percentage points decrease in Ltax. The estimates in column [3] show that a marginal increase in Polinst induces a -3.95 percentage points decrease in Arr. In terms of our theoretical priors, this result points to a relevant role of insiders in shaping the preferences of policymakers in the presence of political instability. While the estimated model implies a common effect of a political shocks - after conditioning on timeinvariant country fixed effects - on labor market institutions across all OECD countries, to get a better understanding of the economic implications of our results, we investigate the predicted outcomes of different political shocks in selected countries (i.e. as described earlier, see section 3.2.). In particular, a one standard deviation in Polinst over the sample describes the outcome of a political shock larger than New Zealand's 1993-1996 electoral reform. ${ }^{25}$ In terms of the baseline specification, such a significant increase in political instability in New Zealand would be associated with an increase in labor market regulation of 0.41 standard deviations, that is, close to 75 percent of the overall variation in the country's $L m r$ indicator over the entire period, a decrease of -1.16 percentage points in the labor tax wedge, and a reduction in the unemployment benefits replacement ratio of about -5.01 percentage points, all sizeable changes compared to the variation in the indicators (Ltax and Arr) over the entire

\footnotetext{
${ }^{25}$ One standard deviation in Polinst over the sample is equal to 1.68 while the 1993-1996 New Zealand electoral reform entailed an increase in Polinst of 1.27. In terms of between country variation, a one standard deviation increase in Polinst in a country in Southern Europe (e.g. Italy, average political instability -0.40) would induce the average degree of political instability of a Nordic country (e.g., Denmark, average Polinst 1.25); conversely, a one standard deviation decrease in Polinst would induce in the same country the average degree of political instability of an Anglo-Saxon country (e.g. between New Zealand characterized by average Polinst of -1.31 and Canada characterized by average -2.36 ).
} 
period -

However, the specification on which the above results are based is too restrictive since it does not allow for multiple dimensions of political instability - such as political turnover and polarization - and totally neglects the possibility of complementarities among political variables. In the rest of this section, we relax both these restrictions and estimate more flexible specifications, reported in Table 1 (columns [4] to [9]). We split political instability into political turnover and polarization and analyze their effects separately on: labor market regulation, the tax wedge, and the unemployment benefits replacement ratio. Since Polturn and Polpolar are standardized, the size of their coefficients in Table 1 (columns [4] to [6]) is directly comparable. ${ }^{26}$ A one standard deviation increase in Polturn and Polpolar is associated with a $0.87+0.12=0.99$ increase in the labor regulation index, and $\mathrm{a}-(1.48+0.71)=-2.19$ and $-(7.13+2.72)=-9.85$ percentage points decrease in the labor tax wedge and the unemployment benefits replacement ratio respectively. To account for complementarities between the political variables, we re-estimate the previous specification augmented with an interaction term (Polturn $*$ Polpolar). The interaction terms are always statistically significant and, in line with the complementarity hypothesis, appear to magnify the effect of political instability on labor market institutions (see columns [7] to [9]). The predicted impact of political instability is larger in countries which are already unstable. For example, in an economy with political polarization above the OECD average (i.e. Polpolar $>0$ ), the partial effect of political turnover on labor market regulation would be given by $1.03+0.20$ Polpolar; similarly, the effect of political polarization would be $0.14+0.20$ Polturn. The figures for the labor tax wedge and unemployment benefits replacement rate are similar. ${ }^{27}$ To get a better idea of the economic magnitude of our results, we can interpret the overall predicted impact of a change in political instability on labor market institutions based on the experience of selected OECD countries. For example, our estimates indicate that the Portuguese process of political stabilization described above, explains about 30 percent of the labor market liberalization that occurred in Portugal over

\footnotetext{
${ }^{26}$ The size of the coefficients of Polturn and Polpolar in columns [4] to [6] is not directly comparable to the size of the coefficients of Polinst in columns [1] to [3]. Polinst is obtained as the sum of Polturn and Polpolar, thus it has a zero mean but no unit standard deviation.

${ }^{27}$ The partial effects on the labor tax wedge are, respectively, political turnover $-(2.09+0.78$ Polpolar $)$ and political polarization $-(0.80+0.78$ Polturn $)$; for unemployment benefits replacement rates, political turnover is $-(8.22+1.38$ Polpolar $)$ and political polarization $-(2.88+1.38$ Polturn $)$.
} 
the period. ${ }^{28} 29$

The estimates in Table 1 indicate important 'complementarities' in the political process such that the same political shock (e.g. a one standard deviation increase in Polturn and Polpolar) will have a different impact on the labor market institutions in countries characterized by different degrees of overall political instability. Consider, for example, countries characterized by low levels of political instability, such as a typical Anglo-Saxon country (somewhere between the UK and the US) with Polturn and Polpolar indicators scoring on average about -1.70 and -0.90 , respectively. In such a country a political shock consisting of a one standard deviation increase in Polturn and Polpolar would increase $L m r$ by 0.65 points, ${ }^{30}$ and reduce Ltax and Arr by -0.86 percentage points and -7.51 , respectively. Conversely, in a highly unstable country, such as a typical Nordic country (something between Sweden and Norway), with Polturn and Polpolar scoring 1.0 and 0.5, respectively, a one standard deviation increase in Polturn and Polpolar could be expected to have a bigger impact on labor market institutions: namely 1.47 for $L m r,-4.1$ for $L t a x$ and -13.2 for Arr.

While it is reassuring that the magnitude of the above results is comparable to some of the changes that occurred in the political setting and welfare system reform implemented in the 1990s in some OECD countries, we need to know whether our political instability indicators are robust to alternative explanations. To address this, Table 2 presents an augmented baseline specification, with alternative political indicators which, as discussed below, emerge as important features of government's propensity for institutional reform. Note that their omission could bias the estimated impact of political instability on labor market institutions. Columns [1]-[3] include a dummy for a leftwing government coalition (Left). The

\footnotetext{
${ }^{28}$ Computed at the Portuguese averages (1.02 for Polturn and -0.48 for Polpolar $)$ and standard deviations (0.09 for Polturn and 0.40 for Polpolar), the estimated coefficients in Table 1 (columns [7] to [9]) suggest an effect on labor market regulation of about $-0.22=1.03 *(-0.09)+0.14 *(-0.40)+0.20 *[(1.02 *(-0.40))+$ $(-0.48 *(-0.09))]-$ i.e. close to 30 of the overall change in $L m r$.

${ }^{29}$ The overall increase in political stability that occurred in Italy during the sample period, accounts for roughly half of the subsequent decrease in labor market regulation. The move of the Italian electoral system from proportional to (quasi) majoritarian representation, significantly reduced the turnover of elected governments, and parties' dispersion in parliament. This favored a massive wave of reforms in the late 1990s which liberalized employment contracts, and moderated union power in wage setting. Computed at the Italian averages (0.25 for Polturn and -0.66 for Polpolar) and standard deviations (0.64 for Polturn and 0.44 for Polpolar $)$ over the sample period, the estimated impact on $L m r$ is $-0.65=1.03 *(-0.64)+0.14 *$ $(-0.44)+0.20 *[(0.25 *(-0.44))+(-0.66 *(-0.64))]-$ i.e. about 53 of the overall change in $L m r$ in the country.

${ }^{30} \mathrm{~A}$ one standard deviation increase in political turnover would increase labor market regulation by 0.85 (i.e. $1.03+0.20 *(-0.90)$ ), while the effect of a one standard deviation increase in political polarization would result in an increase of -0.20 (i.e. $0.14+0.20 *(-1.70)$ ). The combined effect of a one standard deviation increase in Polturn and Polpolar on $L m r$ would be $0.65=(0.85-0.20)$.
} 
political orientation of government has been shown to be an important determinant of the government's stake with respect to the equity versus efficiency trade-off, and government's attitude to labor income and redistribution (see Høj et al. [37]).

[Table 2 here]

Columns [4]-[6] include two dummies for the phase of the legislature: less than two years to the end of the legislature $($ Yrcurnt $\leq 2)$ and less than two years in office for the current government (Yrcurnt $\leq 2$ ). It is generally agreed that, towards the end of a legislature, with a general election impending, governments will refrain from implementing structural reform that might entail high short-term costs and long-term deferred benefits. Conversely, newlyelected governments are more likely to implement reforms whose expected gains during the legislature will be substantial (see Høj et al. [37]). Columns [7]-[9] include a measure of party strength, measured as the age of the governing parties (Prtyage), to capture the idea that a stronger party system will be more representative of stakeholders' interests regardless of the level of political instability (see Enikolopov and Zhuravskaya [30]). This set of estimates confirms the previous results: the magnitude and significance of our indicators of political instability and their interaction do not change. In particular, the leftwing orientation is never statistically significant; the phase of the legislature shows a weak effect only on labor market regulation, suggesting that coeteris paribus regulation might be comparatively higher in legislatures that are coming to an end. Finally, party strength exhibits a (weak) positive association with labor market regulation and a (strong) statistically significant negative effect on the replacement rate, which supports the idea that party systems in modern democracies tend to weigh the interests of insiders more heavily (Saint Paul [43]).

Table 3, columns [1]-[3], check for heterogeneous effects of political instability, investigating the hypothesis that the impact of the political process on labor market institutions may be influenced by a country's legal origins. The idea is that common law countries will rely more heavily on markets, and civil law countries will rely more on regulation (see Glaeser and Shleifer [33], Botero et al. [18]). We interact our political indicators with Civil Law and Common Law dummies which allow for the impact of Polturn and Polpolar to vary according to a country's legal origins. The results are consistent with the hypothesis that political instability may have a larger impact on labor market institutions in civil law countries compared to common law countries. The impact of political turnover on labor regulation and unemployment benefit replacement ratios is larger in civil law countries, while the effect of tax moderation (i.e. on the tax wedge) is not statistically different between the two. 
[Table 3 here]

Political polarization shows a larger (and statistically significant) effect on labor regulation and the tax wedge in civil law compared to common law countries, whilst we find no statistically significant difference between regimes in terms of the unemployment benefit replacement ratios. Finally, we adopt a different measure of political instability, one that is suggested in the literature and is intended to capture movements along the degree of enforcement of democratic institutions (see Alesina and Perotti [8] and Dutt and Mitra [28]). We can measure political instability with an indicator capturing the 'youth' of a democratic institution (Y dem) (see Table 3columns [4]-[6]). Both the size and statistical significance of $Y d e m$ are in line with our theoretical priors and confirm the empirical results, that is, that countries characterized by young democratic institutions present a higher degree of labor market regulation and lower tax wedge and replacement rates compared to more mature democracies.

One cause for concern with respect to the previous estimates is the possibility that the political process might not be exogenous to government choices related to labor regulation, taxation, and unemployment insurance. While it is true that the political process is responsible for setting the agenda, and designing and implementing policy interventions in the labor market, it is true also that political instability - such as the dropping of veto players or the emergence of minority or extremist positions in parliament - might be affected by a (lack of) institutional reforms or, alternatively, that electoral and political reforms are the outcome of social turmoil, which means that institutions are held responsible for dismal economic performance. ${ }^{31}$ In this respect, if (reverse) causality also runs from labor market institutions to political instability, OLS estimates are likely to be biased and alternative estimation methods will be needed. Our empirical strategy is based on instrumental variables (IV) and General Method of Moments (GMM) methods, and estimation of a baseline equation instrumenting current political instability (our overall indicator, Polinst $_{\text {) with }}$ long-run lags of political turnover and polarization and their interaction (we use 10 years lags, i.e. Polturn Po-10 $_{t}$, Polpolar ${ }_{t-10}$ and Polturn $_{t-10} *$ Polpolar $\left._{t-10}\right)$. Finding instruments for political instability (e.g. political shock or reforms), for the reasons discussed above, is

\footnotetext{
${ }^{31}$ There is some anecdotal evidence supporting this view. E.g. in Sweden, in the 1990s, several governments lost political support and were dismissed when they tried to reform the system of unemployment insurance. In New Zealand, the electoral reform that introduced a proportional system was triggered by workers' discontent following the Labor party's defeat in two consecutive elections. In the aftermath of the financial crisis, reforms to the labor market institutions in several European countries - e.g. Spain, Greece and Italy - have triggered changes in the functioning of the political process.
} 
not straightforward but we argue that using historical political indicators for past legislatures, that vary across countries and over time, constitutes a reasonable source of exogenous variation to identify the parameter of interest. In practice, we assume that Polturnt-10, Polpolar $_{t-10}$ and Polturn $_{t-10} *$ Polpolar $_{t-10}$ affect labor market institutions only through their impact on current Polinst, not directly. ${ }^{32}$

Table 4 reports the main results and the statistical tests: columns [1]-[3] report the IV estimates and columns [4]-[6] report the GMM estimates. The effect of overall political instability on the different indicators of labor market institutions is always statistically significant and has the correct sign. Statistical tests reject the hypotheses that the model is under-identified or that the instruments are weak; the Hansen- $J$ test for over-identification does not reject the hypothesis that the instruments provide valid exclusion restrictions. Comparing the IV estimates with the previous results (columns [1]-[3] in Table 3), identifies a larger effect of political instability, which would suggest that the previous OLS results might have been biased downwards.

[Table 4 here]

We conduct several additional sensitivity analyses to check the robustness of our results, for the baseline and for our preferred specification (see Table 5, panels A-C). Columns [1]-[3] provide alternative specifications and estimation methods to control for unobserved country specific shocks and omitted variable bias related to unobservables in the economic and political cycles. In particular, we add country specific time trends (column [1]), then replace the time-fixed effects with a Correlated Common Effect Pooled (CCEP) estimator (Pesaran [41]) which accounts for the presence of cross-section correlated error terms (column $[2])$.

\section{[Table 5 here]}

Lastly, we replace the economic crisis dummy with other business cycle variables such as the output gap and the real exchange rate (column [3]). All the estimated coefficients, in each of the labor market institution equations, confirm the previous results suggesting that our results are not driven by unobserved shocks or cyclical factors. In columns [4] and [5] we control for the potentially confounding role of unemployment and government expenditures by adding controls for lagged unemployment rate and lagged government deficit. While these variables (particularly past unemployment rate) have strong explanatory power, the

\footnotetext{
${ }^{32}$ We generate fitted values of Polinst by performing a nonlinear first stage. This identification strategy generates consistent estimates provided that the first stage nonlinear model is correctly specified (see also Angrist and Krueger [10]).
} 
estimates of the political instability indicators do not change with the inclusion of these potentially omitted variables. The section on descriptive statistics shows that, during the period considered, some countries exhibit considerable variation in political instability; we need to confirm that our results are not driven by the behavior of these countries. In columns [6]-[8], we check the robustness of the results against the exclusion of selected countries (e.g. New Zealand, Italy and Portugal) characterized by large political shocks. Column [9] excludes the Nordic countries since their peculiar institutional setting may not be characterized by such high political instability as the indicators would imply. The estimates confirm the previous findings suggesting that our results are not affected by potential outliers. Finally, in column [10], to smooth the variation in our data and investigate the medium-run properties of our estimates, we run our regressions using three years averages. No significant changes emerged.

\section{Concluding remarks}

This paper investigated the relationship between political instability and labor market institutions. We argue that some features of the political process are important determinants of policymakers' choices over the regulatory framework of the labor market. We showed that political turnover and political polarization, by reducing the future yields of policy interventions, introduce a negative externality inducing incumbent governments to create rents and divert resources from public good provision and unemployment insurance. We tested these predictions empirically using panel data for 21 OECD countries for the period 1985-2006. We found robust evidence of political turnover and political polarization being associated with higher levels of labor market regulation, lower unemployment benefit replacement rates, and a smaller tax wedge on labor. Also strong complementarities between the different dimensions of political instability are detected: the impact of political turnover on labor market institutions is found to be larger in more polarized political systems, while high political turnover reinforces the effect of political polarization. The analysis was extended to evaluate the robustness of our results to a number of alternative specifications and different definitions of political instability, and to address the potential endogeneity of the political instability variables. The results proved to be robust to most alternative specifications, while OLS estimates were shown to underestimate the effects of political instability on labor market institutions. 
An interesting implication of the above results, which so far has not been explored, is the expected effects of political instability - which operates through the optimal choices of government in terms of labor regulation, labor tax wedge and unemployment benefits replacement rates - on unemployment patterns. In this respect, the analysis links the extensive literature on the effects of (exogenous) labor market institutions on unemployment with the political process underlying policy-making decisions. Our analysis suggests that, for the average OECD country, the predicted impact of a one standard deviation increase in political instability is likely to increase unemployment by about 2.3 percentage points. ${ }^{33}$ Note that this is a sizeable effect, which is able to explain up to 58 percent of the total variation in the unemployment rate in our sample. Moreover, as discussed above, complementarities among the different dimensions of the political process amplify and differentiate the effects of political instability between high and low political instability countries. In practice, we find that a shock equal to one standard deviation increase in political turnover and polarization would imply an increase in the unemployment rate of about 3.1 percentage points in a high instability country (e.g. above the OECD average, such as Continental European or Nordic countries), while the effect on unemployment in a low instability country (e.g. below the OECD average, such as the Anglo-Saxon countries) would be less than 0.9 percentage points.

These findings have some interesting policy implications. For example, the attempts made by international organizations to urge governments to reform their labor market institutions should take account of the stability of the particular political systems. More unstable and more polarized systems are likely to experience greater resistance to reform of their labor market institutions. This explains why reforms that minimize opposition from social groups with vested interests, such as two-tier reforms, tend to be more successful. The experience of some countries shows also that when the political setting changes, either as the result of a constitutional reform or a change in the electoral rules, the effects on labor market institutions and unemployment can be significant and persistent. Finally, any measure taken to reduce the ability of the political system to create rents, such as increasing market competition or reducing bargaining power, will benefit workers in terms of both lower unemployment probability as well as higher public good provision.

\footnotetext{
${ }^{33}$ Our results (not reported here, but available on request) are based on a model that estimates the impact of political instability on unemployment, via the effect on labor market institutions. Using IV and GMM we estimated an unemployment equation jointly with three equations for different labor market institutions. In line with the literature, we controlled for a wide range of factors that may affect unemployment, such as aggregate demand and supply, economic cycle, trade openness, occurrence of macroeconomic shocks, and country and time fixed effects. A battery of tests confirmed the validity of our estimation method.
} 
Figure 1: Patterns of political turnover and political polarization

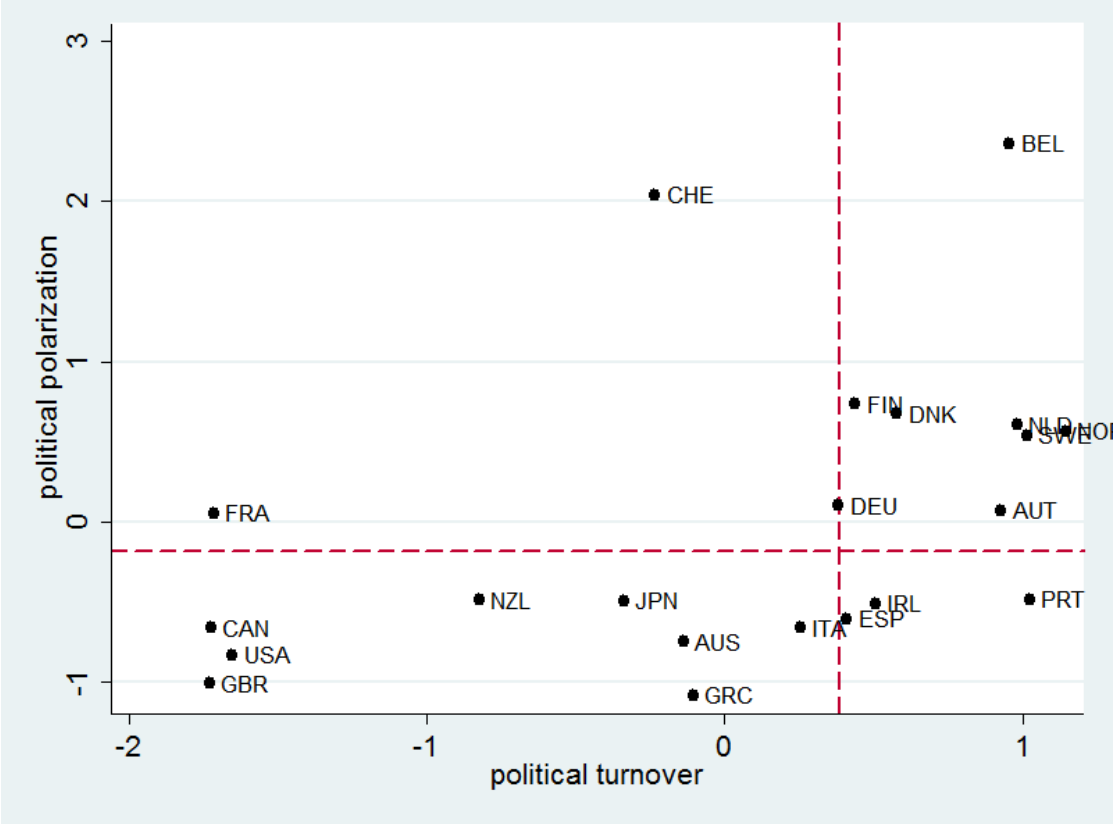

Sources: World Bank DPI.

Notes: country averages over the period 1985/2006. 
Figure 2: Political instability and labor market institutions
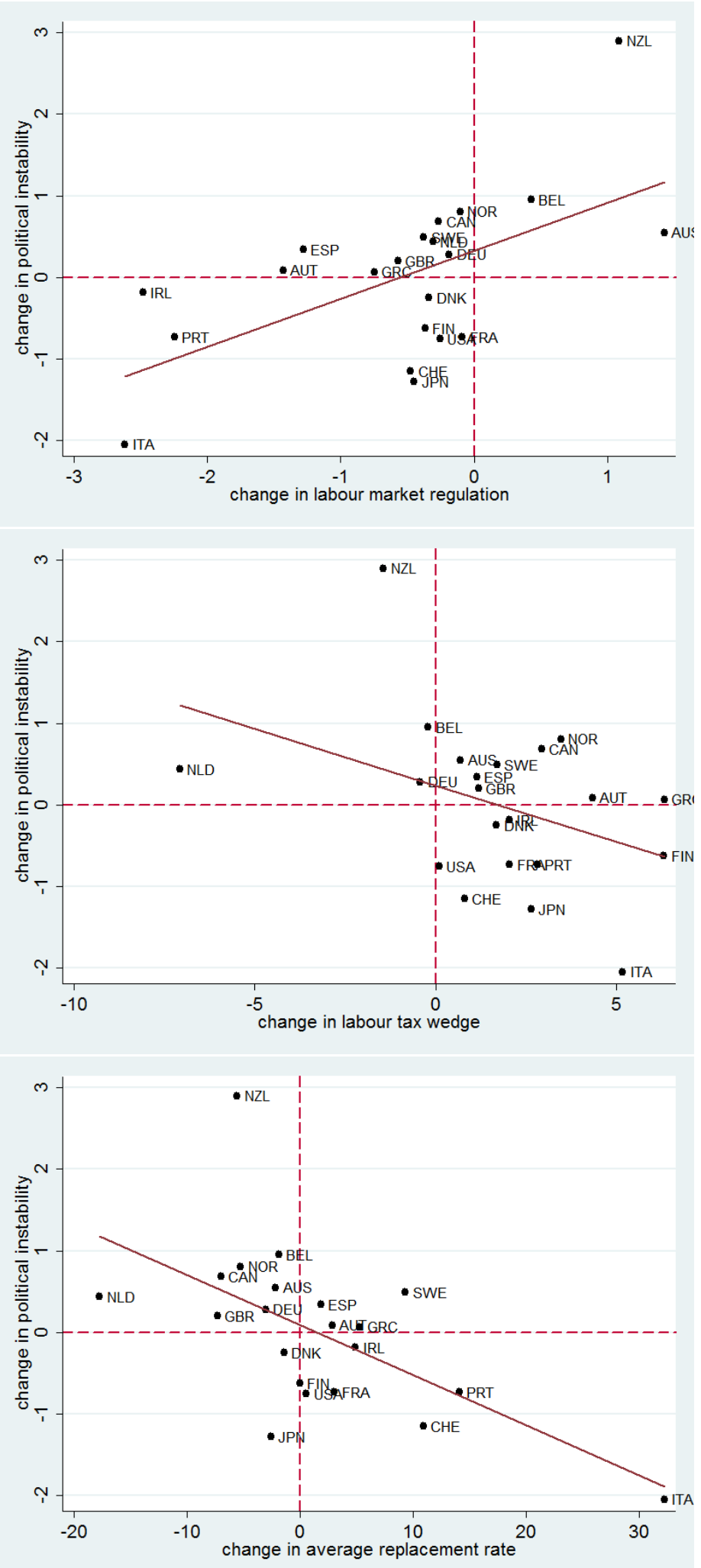

Notes: differences in averages over the sub periods 2004/06 and 1985/87 


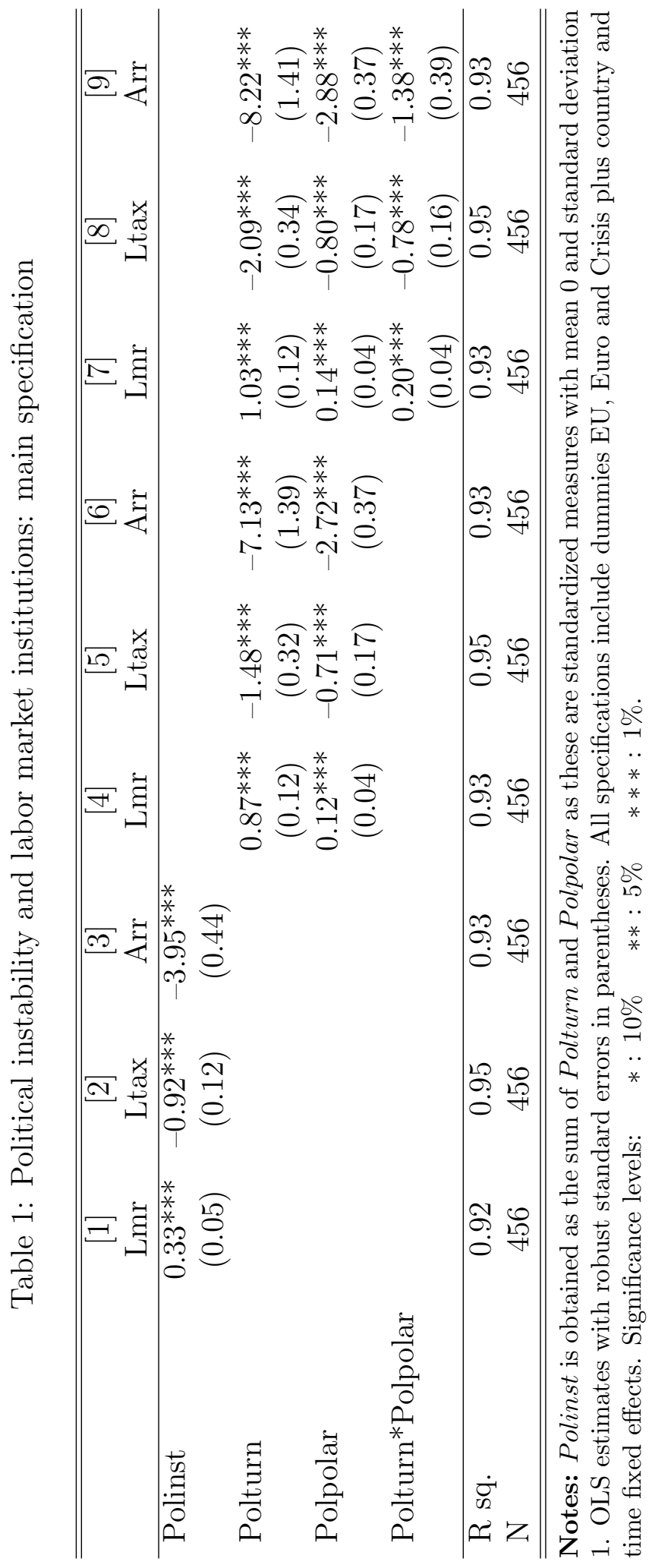




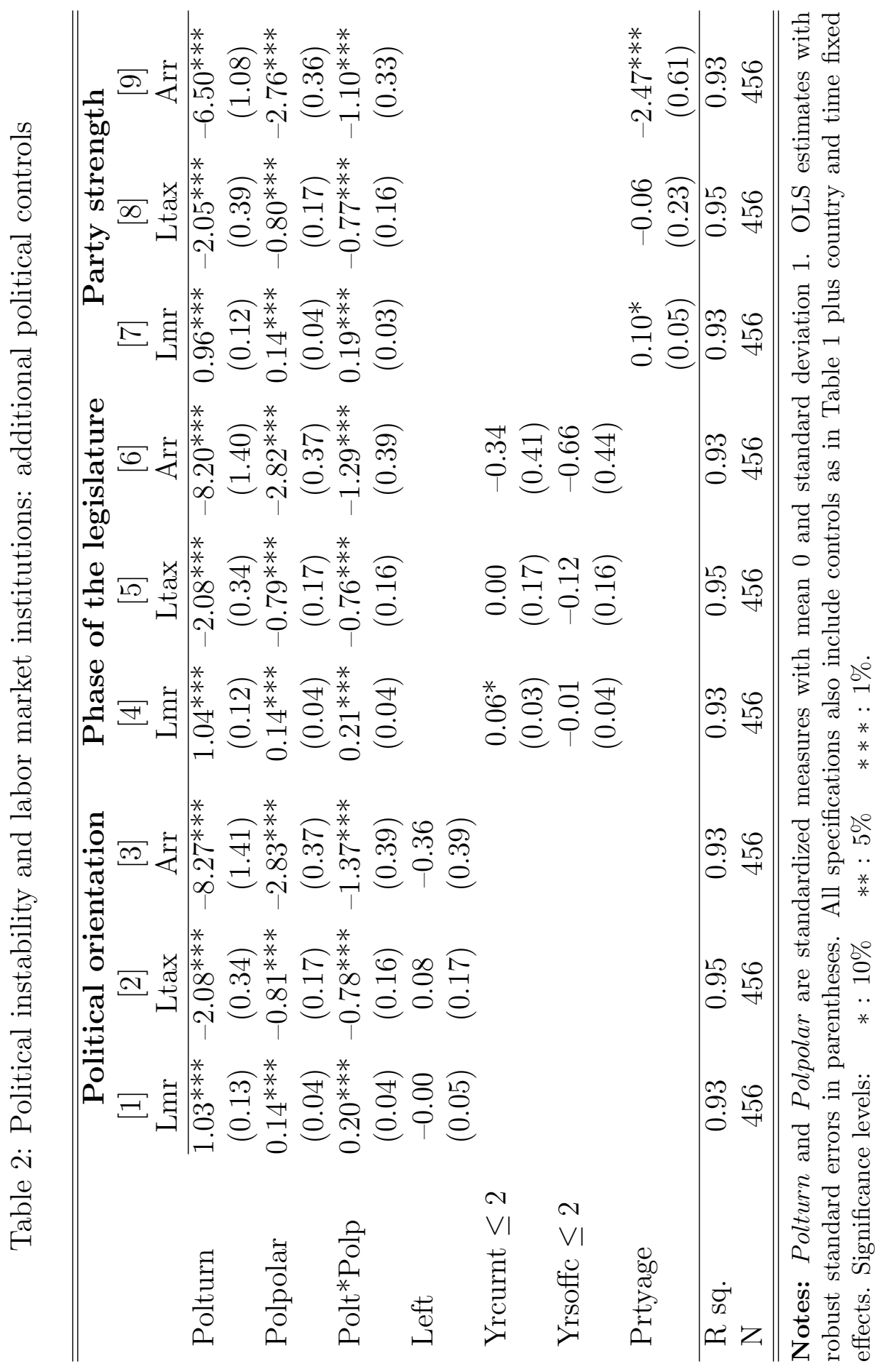




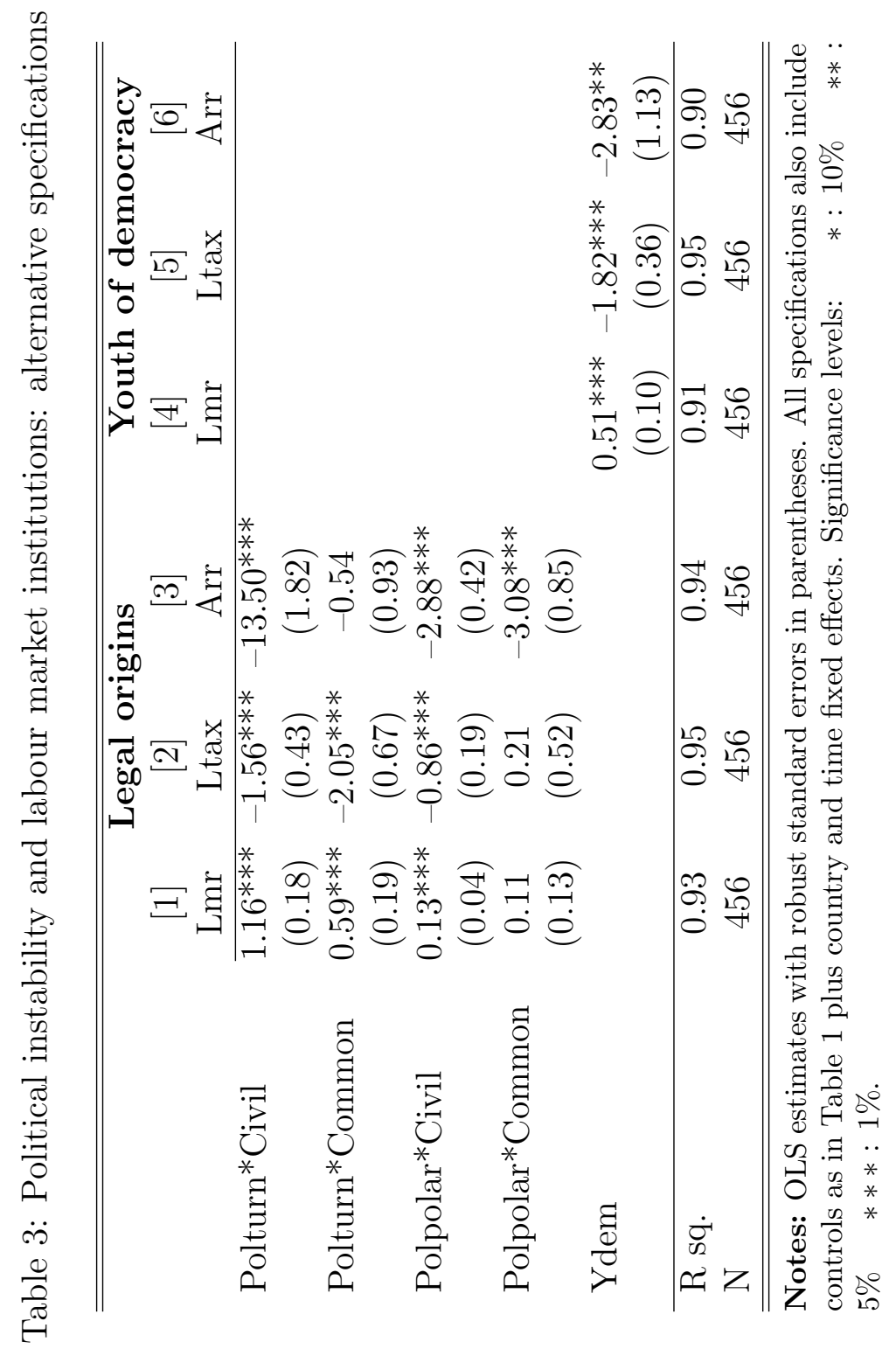




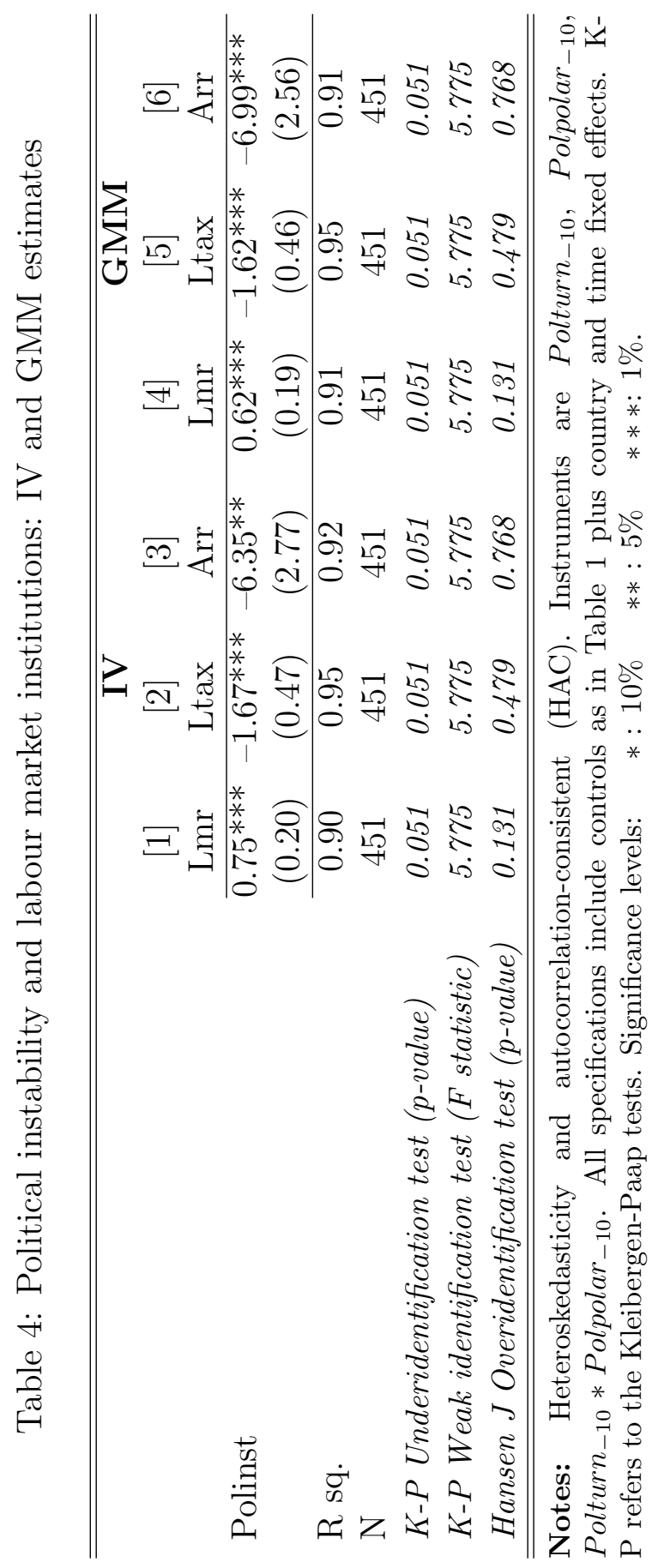




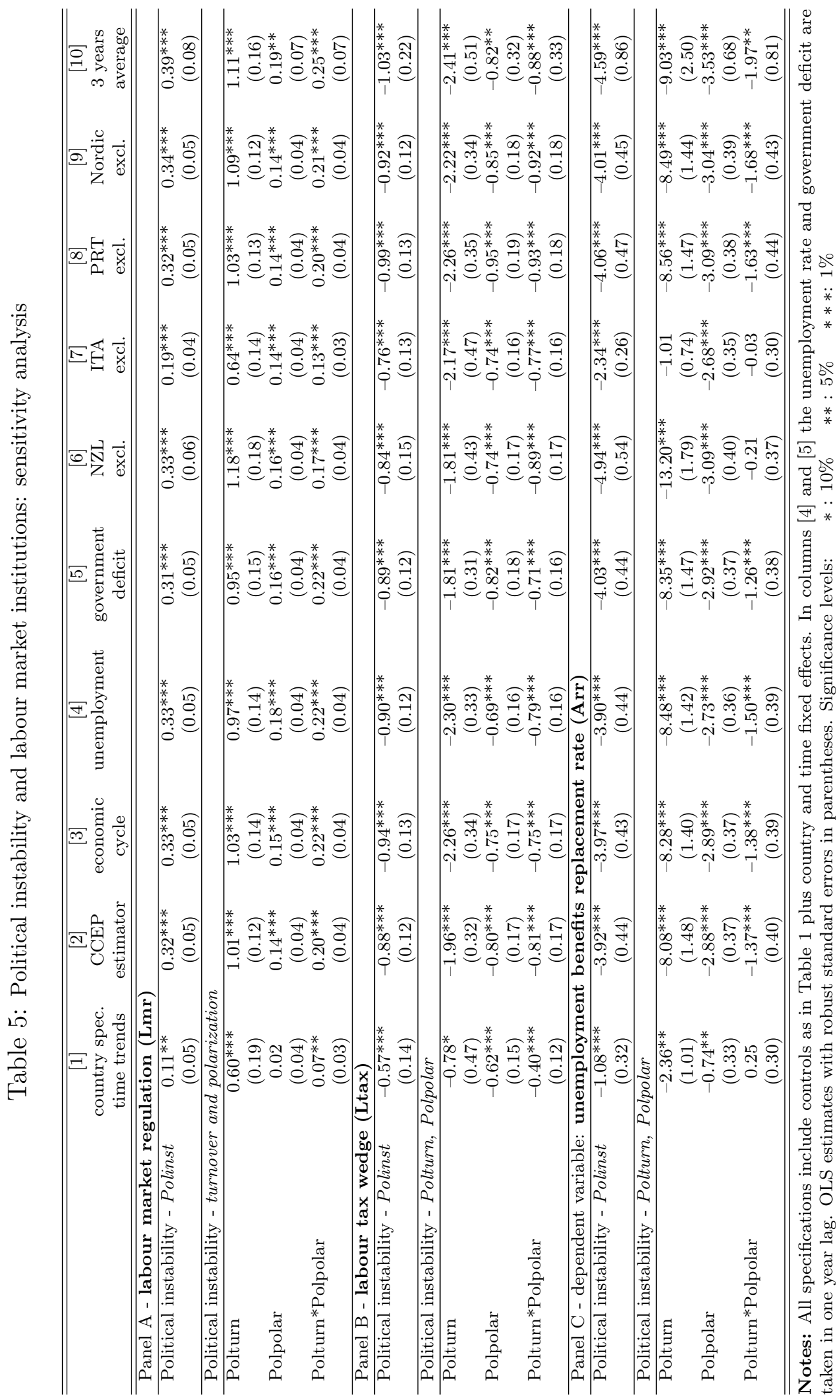




\section{References}

[1] Abreu, R. and F. David (2010), "Socially responsible behaviour: labour market in Portugal", Polytechnical Studies Review, Vol. VIII (13), 103-127.

[2] Aghion P., A. Alesina and F. Trebbi (2004), "Endogenous political institutions", Quarterly Journal of Economics, 119 (1): 565-611.

[3] Aghion, P., Algan, Y. Cahuc, P. and A. Shleifer (2010), "Regulation and distrust", Quarterly Journal of Economics, 125(3), 1015-49.

[4] Alesina A., Ozler S., Roubini N., and P. Swagel (1996), "Political Instability and Economic Growth", Journal of Economic Growth, 1, 189-211.

[5] Alesina A., Ardagna, S. and F. Trebbi (2006), "Who adjust and when? On the political economy of reforms", NBER Working Paper, No. 12049.

[6] Alesina, A. Ardagna, S., Nicoletti G. and Schiantarelli F. (2005), "Regulation and Investment", Journal of the European EconomicAssociation 3(4), 791-825.

[7] Alesina, A. and A. Drazen (1991), "Why are stabilization delayed?", American Economic Review, 81, 1170-88.

[8] Alesina A. and R. Perotti (1993), "Income distribution, political instability and investments", European Economic Review, Vol. 40(6), 1203-1228.

[9] Anesi, V. and P. De Donder (2009), "Party formation and minority ideological positions", The Economic Journal 119 (October), 1303-1323.

[10] Angrist, J.D. and A.B. Krueger (2002), "Instrumental Variables and the Search for Identification: From Supply and Demand to Natural Experiments", Journal of Economic Perspectives 15:4, pp. 69-85.

[11] Arpaia A. and Mourre G., (2010), "Institutions and performance in European labour markets: taking a fresh look at evidence", Journal of Economic Surveys, 2-48.

[12] Azzimonti, M. (2011), "Barriers to Investment in Polarized Societies", American Economic Review, 101, 2182-2204. 
[13] Barro, R.J. (1991), "Economic Growth in a Cross Section of Countries", Quarterly Journal of Economics, 106 (2), 407-443.

[14] Bassanini A. and R. Duval (2009), "Unemployment, institutions and reform complementarities: re-assessing the aggregate evidence for OECD countries", Oxford Review of Economic Policy, 25 (1).

[15] Beck, T., G. Clarke, A. Groff, P. Keefer, and P. Walsh (2001), "New Tools in comparative political economy: The Database of Political Institutions", World Bank Economic Review 15. 165-176.

[16] Blanchard, O. and L. Summers (1986), "Hysteresis and the European Unemployment Problem", NBER, Working Paper No. 1950.

[17] Blanchard, O. and J. Wolfers (2000), "The role of shocks and institutions in the rise of European unemployment: the aggregate evidence", Economic Journal 110/462: C1-C33.

[18] Botero J., Djankov S., La Porta R., Lopez-de-Silanes F. and Shleifer A. (2004), "The Regulation of Labor", Quarterly Journal of Economics, 119(4), 1339-1382.

[19] Brügemann, B. (2006), "Does Employment Protection Create Its Own Political Support?", IZA Discussion Paper No. 2286, September.

[20] Buti, M., Turrini A., Van den Noord, P. and P. Biroli (2008), "Defying the Juncker Curse: can reformist governments be re-elected?", European Economy Economic Papers No. 324, May.

[21] Carey, D. and J. Rabesona (2002), "Tax ratios on labour and capital income and on consumption", OECD Economic Studies No. 35, 2002/2.

[22] Carmignani, F. (2003), "Political instability, uncertainty and economics", Journal of Economic Surveys, 17, 1-54.

[23] Castles, F.G. and Mitchell, D. (1993), "Worlds of welfare and families of nations", in F. G. Castles (Ed.), Families of Nations: Patterns of Public Policy in Western Democracies, Aldershot: Dartmouth. 
[24] Coe, D. T., and Snower, D. J. (1997), "Policy Complementarities: The Case for Fundamental Labour Market Reform", IMF Staff Papers, 44(1), 1-35.

[25] Cukierman, A., Edwards, S. and G. Tabellini (1992), "Seigniorage and political instability", American Economic Review 82, 537-556.

[26] Diermeier, D. and R. T. Stevenson (1999), "Cabinet survival and competing risks", American Journal of Political Sciences, 43, 1051-1068.

[27] Devereux, M. and J.F. Wen (1998), "Political instability, capital taxation and growth", European Economic Review 42, 1635-1651.

[28] Dutt, P. and D. Mitra (2008), "Inequality and the Instability of Polity and Policy", Economic Journal, 118, 1285-1314.

[29] Duval, R. (2008), "Is there a role for macroeconomic policy in fostering structural reforms? Panel evidence from OECD countries over the past two decades", European Journal of Political Economy 24, pp. 491-502.

[30] Enikolopov, R. and E. Zhuravskaya (2007), "Decentralization and political institutions", Journal of Public Economics 91, pp. 2261-2290.

[31] Fabrizio, S. and A. Mody (2006), "Can budget institutions counteract political indiscipline?", Economic Policy, Vol. 21 (48), pp. 689-739.

[32] Freeman, R.B. (2008), "Labor Market Institutions Around the World", LSE-CEP Discussion Paper No 844.

[33] Glaeser, E. and Shleifer, A. (2002), "Legal Origins", Quarterly Journal of Economics, 117, 1193-1230.

[34] Griffith, R., Harrison R. and G. Macartney (2007), "Product market reforms, labour market institutions and unemployment", The Economic Journal 117, C142-C166.

[35] Grofman B. and Van Roozendaal P., (1997), "Modelling Cabinet Durability and Termination", British Journal of Political Science, 27 (3), 419-451.

[36] Hibbs, D. (1973), "Mass political violence: a cross-sectional analysis", Wiley and Sons, New York. 
[37] Høj, J., Galasso, V., G. Nicoletti and T. Dang (2006), "The Political Economy of Structural Reforms: Empirical Evidence from OECD countries", OECD Economics Department Working Paper, No. 501, OECD.

[38] Milesi-Ferretti, G.M., Perotti, R. and M. Rostagno (2002), "Electoral Systems And Public Spending", Quarterly Journal of Economics, 117(2), 609-657.

[39] Pagano, M., and P. Volpin (2006), "The Political Economy of Corporate Governance", American Economic Review", 95(4), 1005-1030.

[40] Persson, T. and L.E.O. Svensson, (1989), "Why a Stubborn Conservative would Run a Deficit: Policy with Time-Inconsistent Preferences", Quarterly Journal of Economics, 104 (2) 325-345.

[41] Pesaran, M.H., (2006), "Estimation and Inference in large heterogeneous panels with a multi-factor error structure", Econometrica, 74 (1) 967-1012.

[42] Saint-Paul G., (1996), "Exploring the Political Economy of Labour Market Institutions", Economic Policy 23, 265-315.

[43] Saint-Paul G., (2002), "The Political Economy of Employment Protection", The Journal of Political Economy, Vol. 110, No. 3, (June) pp. 672-704.

[44] Stern, N. (1987), "The Effects of Taxation, Price Control and Government Contracts in Oligopoly and Monopolistic Competition", Journal of Public Economics 32: 133-158.

[45] Svensson L.E.O. (1998), "Investment, property rights and political instability: Theory and evidence", European Economic Review, 42 (1998) 1317-1341.

[46] Tsebelis G. and E. Chang (2004), "Veto Players and the Structure of Budgets in Advanced Industrialized Countries", European Journal of Political Research, 43(3), 449476.

[47] Vindigni A. (2008), "Uncertainty and the politics of employment protection", IZA Discussion Paper No. 3509. 


\section{Appendix A Theoretical model}

\section{Appendix A.1 Proof of Lemma}

In period 1, government chooses its fiscal policy taking as given the labor market policy set one period earlier. From (6) the composition of the public good preferred by party $a$ is obtained as a solution of the following:

$$
\gamma g_{1 a}=(1-\gamma) g_{2 a}
$$

Condition (A-1), given total public expenditure $z=g_{1}+g_{2}$, leads to the optimal allocation (8). If we substitute (8) in (6) we obtain party a's utility from public consumption when party $a$ can itself implement its preferred composition of the public good:

$$
G_{a}^{a}\left(g_{1 a}, g_{2 a}\right)=z
$$

We now turn to the choice of the optimal labour tax rate. As in period 1, party a faces a probability $p=0$ to be removed and replaced by its competitor. From equation (5) and (A-2) it holds $E\left[G^{a}\right]=G_{a}^{a}=z$. From (4) party a's maximization problem can be written as follows:

$$
\max _{\tau} V_{1} \equiv E[I]+\delta z
$$

where workers' welfare is given by (3) and subject to the budget constraint (7). The first order condition is:

$$
\delta l+[w-v+\delta(\tau+v)] l_{c}^{\prime}=0
$$

The second order condition for the concavity of the welfare function is: ${ }^{34}$

\footnotetext{
${ }^{34}$ For notational simplicity, in the welfare analysis below we omit the subscript 1 and denote welfare in period 1 simply by $V$.
} 


$$
V_{\tau \tau}^{\prime \prime}=2 \delta l_{c}^{\prime}+[w-v+\delta(\tau+v)] l_{c c}^{\prime \prime}<0
$$

The negative second order derivative confirms that $V$ is strictly concave in the labor tax thus $V_{\tau}^{\prime}$ is invertible. Let $T:=\left(V_{\tau}^{\prime}\right)^{-1}$ be defined in a contour of $\widetilde{\mu}>0$ and $\widetilde{v}>\bar{v}$ such that $V_{\tau}^{\prime}=0$ i.e. the maximization problem (A-3) admits an interior solution $\tau^{*}=T(\mu, v)$ for any $\mu>\widetilde{\mu}$ and $v>\widetilde{v}$.

To observe the impact of labor market policy on the equilibrium labor tax it is useful to derive the optimal tax rule in the presence of a perfectly competitive labor market (i.e. when $\mu=0$ and $v=\bar{v})$ :

$$
\delta l+\delta(\tau+\bar{v}) l_{c}^{\prime}=0
$$

This implicitly defines the optimal labor tax in the presence of a perfectly competitive labor market $\tau^{\max }$ as in statement (i) of the Lemma. From $(\mathrm{A}-6), \epsilon_{l c}^{\tau^{\max }}=-l_{c}^{\prime}(\tau+\bar{v}) / l=1$ which implies that any tax increase evaluated at $l\left(\tau^{\max }+\bar{v}\right)$ will be revenue neutral. From (A-4) it can be easily seen that, when $\mu>0$ and $v>\bar{v}$, at the tax equilibrium the elasticity of labor demand is $\epsilon_{\tau^{*}}^{l c}=-l_{c}^{\prime}\left(\tau^{*}+w\right) / l=1-(\delta-1)(w-v) l_{c}^{\prime}>\epsilon_{l c}^{\tau^{\max }}$, which implies that $\tau^{*}<\tau^{\max }$, as in statement (ii) of the Lemma. We can finally apply the implicit function theorem:

$$
\begin{aligned}
& T_{\mu}^{\prime}=-\frac{\partial V_{\tau \mu}^{\prime \prime}}{\partial V_{\tau \tau}^{\prime \prime}}=-w_{\mu}^{\prime} \frac{(\delta+1) l_{c}^{\prime}+[w-v+\delta(\tau+v)] l_{c c}^{\prime \prime}}{2 \delta l_{c}^{\prime}+[w-v+\delta(\tau+v)] l_{c c}^{\prime \prime}}=\frac{-w_{\mu}^{\prime}[(\delta+1)+\Omega]}{2 \delta+\Omega}<0, \quad(\mathrm{~A}-7) \\
& T_{v}^{\prime}=-\frac{\partial V_{\tau v}^{\prime \prime}}{\partial V_{\tau \tau}^{\prime \prime}}=-\frac{w_{v}^{\prime}\left[(\delta+1) l_{c}^{\prime}+(w-v+\delta(\tau+v)) l_{c c}^{\prime \prime}\right]-(\delta-1) l_{c}^{\prime}}{2 \delta l_{c}^{\prime}+[w-v+\delta(\tau+v)] l_{c c}^{\prime \prime}}=\frac{w_{v}^{\prime}}{w_{\mu}^{\prime}} T_{\mu}^{\prime}-\frac{\delta-1}{2 \delta+\Omega}<0,
\end{aligned}
$$

where $\Omega=[w-v+\delta(\tau+v)] \frac{l_{c c}^{\prime \prime}}{l_{c}^{\prime}}>0$. From (A-7) we can derive statement (iii) in the Lemma. As $\epsilon_{l c}^{\tau^{*}}>1$ any labor market policy that increases the cost of labor imposes a tax penalty on aggregate employment; thus government may increase the tax revenue by keeping the labour tax low. 


\section{Appendix A.2 Expected utility from public good provision}

Party $b$ in period 1 will derive its optimal composition of the public good from the $G_{i}^{b}$ function, obtained symmetrically by replacing $1-\gamma$ to $\gamma$ in (6):

$$
g_{1 b}=\gamma z, \quad g_{2 b}=(1-\gamma) z
$$

By plugging (A-9) into (6) we obtain the utility from public good consumption which accrues to party $a$, based on the combination of public good provision chosen by party $b$ :

$$
G_{b}^{a}=\left(\frac{1}{\gamma(1-\gamma)}\right) \min \left[\gamma^{2} z,(1-\gamma)^{2} z\right]=\frac{\gamma}{1-\gamma} z
$$

where $\gamma \in(1 / 2,1)$. If we substitute $(\mathrm{A}-2)$ and (A-10) in (5) we obtain the expected utility from the public good provision of party $a$ :

$$
E\left[G^{a}\right]=\phi(p, \gamma) z \quad \text { where } \phi(p, \gamma)=1-\frac{p}{\gamma}(2 \gamma-1)
$$

Plug (A-11) and (3) into (4) to obtain (10) in the main text. We can thus derive the 'effective' marginal utility from public good provision:

$$
\omega(\delta, p, \gamma)=\delta \phi(p, \gamma)=\delta\left[1-\frac{p}{\gamma}(2 \gamma-1)\right]
$$

It readily follows:

$$
\begin{aligned}
& \omega_{p}^{\prime}=-\frac{\delta(2 \gamma-1)}{\gamma}<0, \quad \omega_{\gamma}^{\prime}=-\frac{\delta p}{\gamma^{2}}<0 \\
& \lim _{\substack{\gamma \rightarrow 1 \\
p \rightarrow 1}} \delta\left[1-\frac{p}{\gamma}(2 \gamma-1)\right]=0 ; \\
& \lim _{p \rightarrow 0} \delta\left[1-\frac{p}{\gamma}(2 \gamma-1)\right]=\lim _{\gamma \rightarrow 1 / 2} \delta\left[1-\frac{p}{\gamma}(2 \gamma-1)\right]=\delta
\end{aligned}
$$

which proves statement (i)-(iii) in (11). 


\section{Appendix A.3 Proof of proposition 1}

In period $0, v=\bar{v}$ and government chooses $\mu$ to maximize (10) subject to the budget constraint $Z(\mu, \bar{v})$ and the incentive compatibility constraints $T(\mu, \bar{v})$ :

$$
\max _{\mu} E[V] \equiv \bar{V}_{0}+\eta[\bar{v}+(w-\bar{v}) L(\mu, \bar{v})+\omega(\delta, p, \gamma) Z(\mu, \bar{v})]
$$

where

$$
\begin{aligned}
& L(\mu, \bar{v})=l(w+T(\mu, \bar{v})) \\
& Z(\mu, \bar{v})=T(\mu, \bar{v}) L(\mu, \bar{v})-[1-L(\mu, \bar{v})] \bar{v}
\end{aligned}
$$

The first order condition is:

$$
V_{\mu}^{\prime}=W_{\mu}^{\prime} L+(w-\bar{v}) L_{\mu}^{\prime}+\omega(\delta, p, \gamma) Z_{\mu}^{\prime}
$$

From (A-15), the impact of the labour market regulation on employment and public good provision in period 1 , are respectively:

$$
\begin{aligned}
& L_{\mu}^{\prime}=l_{c}^{\prime}\left[W_{\mu}^{\prime}+T_{\mu}^{\prime}\right]<0, \\
& Z_{\mu}^{\prime}=T_{\mu}^{\prime} L(\mu, v)+[T(\mu, v)+v] L_{\mu}^{\prime}<0 .
\end{aligned}
$$

Plug (A-17) and (A-7) in (A-16), and evaluate it at the employment level determined by the optimal tax rule in period 1 (A-4). After some simplification we obtain the first order derivative:

$$
V_{\mu}^{\prime}=\frac{(w-\bar{v})(\delta-1) l_{c}^{\prime}}{\delta}+[\omega(\delta, p, \gamma)-1]\left(\tau^{*}+\bar{v}\right) l_{c}^{\prime}-[1-\phi(p, \gamma)] \frac{(w-\bar{v})[(\delta+1)+\Omega]}{(2 \delta+\Omega)}
$$

We next turn to the proof of statements (i)-(iii) in Proposition 1 . In the case $\phi(p, \gamma)=1$, 
which corresponds to full political stability the first order condition becomes:

$$
V_{\mu}^{\prime}=\frac{(w-\bar{v})(\delta-1) l_{c}^{\prime}}{\delta}+(\delta-1)(T+\bar{v}) l_{c}^{\prime}<0
$$

that is, labor market regulation has a negative impact on welfare, thus government chooses the corner solution $\mu^{*}=0$ which proves statement (i) in Proposition 2. In the more general case of $\phi(p, \gamma)<1$, provided that the second order condition is satisfied (i.e. $\left.V_{\mu \mu}^{\prime \prime}<0\right), V_{\mu}^{\prime}$ is invertible. Thus a function $M:=\left(V_{\mu}^{\prime}\right)^{-1}$ exists in a contour of $\bar{p}<1, \bar{\gamma}<1$

such that $V_{\mu}^{\prime}=0$, that is, the maximization problem (A-14) admits an interior solution $\mu^{*}>0$ for any $p>\bar{p}$ and $\gamma>\bar{\gamma}$. This proves statement (ii). Apply the implicit function theorem to obtain:

$$
M_{k}^{\prime}=-\frac{V_{\mu j}^{\prime \prime}}{V_{\mu \mu}^{\prime \prime}}=-\frac{\left[\omega_{j}^{\prime}\left(\tau^{*}+\bar{v}\right)-\phi_{j}^{\prime} \frac{(w-\bar{v}) T_{\mu}^{\prime}}{w_{\mu}^{\prime}}\right] l_{c}^{\prime}}{V_{\mu \mu}^{\prime \prime}}>0, \quad k=p, \gamma
$$

This proves statement (iii) of Proposition 1.

\section{Appendix A.4 Proof of proposition 2}

Rewrite the optimal tax rule when $v=\rho w$ :

$$
\delta l+[w(1-\rho)+\delta(\tau+\rho w)] l_{c}^{\prime}=0
$$

which defines the equilibrium labor tax as a function of $\mu$ and $\rho$ :

$$
\begin{aligned}
& T_{\mu}^{\prime}=\frac{-\Psi_{\mu}^{\prime}[(\delta+1)+\rho(\delta-1) \Omega]}{2 \delta+\Omega}<0, \\
& T_{\rho}^{\prime}=\frac{\Psi_{\rho}^{\prime}}{\Psi_{\mu}^{\prime}} T_{\mu}^{\prime}-\frac{w(\delta-1)}{2 \delta+\Omega}<0 .
\end{aligned}
$$

The government in period 0 chooses $\mu$ and $\rho$ to maximize (16) subject to its budget constraint and the optimal tax rule in period 1. After some simplifications, we obtain the first order derivatives: 


$$
\begin{aligned}
V_{I \mu}^{\prime}= & \frac{(1-\omega) \rho}{1-\rho}+\alpha l_{0}+(1-\alpha-\rho \phi) w l_{c}^{\prime}-\frac{(1-\alpha)(1-\rho) w l_{c}^{\prime}}{\delta}+ \\
& -(1-\alpha-\omega)\left(\tau^{*}+\rho w\right) l_{c}^{\prime}+(1-\alpha-\phi) \frac{w T_{\mu}^{\prime} l_{c}^{\prime}}{\Psi_{\mu}^{\prime}} ; \\
V_{I \rho}^{\prime}= & \Psi_{\rho}^{\prime} V_{I \mu}^{\prime}-\frac{(\omega-1)(1-L) w}{1-\rho}+(1-\alpha-\phi) w \widehat{T}_{\rho}^{\prime} l_{c}^{\prime}-\frac{\alpha w\left(l_{0}-L\right)}{1-\rho} .
\end{aligned}
$$

where $\widehat{T}_{\rho}^{\prime}=T_{\rho}^{\prime}-\frac{\Psi_{\rho}^{\prime}}{\Psi_{\mu}^{\prime}} T_{\mu}^{\prime}=-\frac{w(\delta-1)}{2 \delta+\Omega}$. Provided that the second order conditions are satisfied (i.e. $V_{\mu \mu}^{\prime \prime}<0$ and $V_{\rho \rho}^{\prime \prime}<0$ ), in the presence of political instability, that is, when $\phi(p, \gamma)<1$, the first order condition $V_{I \mu}^{\prime}=0$ identifies an interior solution and the first term in (A-22) disappears. This implies that government targets $\mu$ to set wages at the desired level and $\rho$ to provide workers with the optimal level of unemployment insurance. We thus obtain (17) in the main text. As $V_{\rho \rho}^{\prime \prime}<0, V_{\rho}^{\prime}$ is invertible and a function $\Upsilon:=\left(V_{\rho}^{\prime}\right)^{-1}$ exists in a contour of $\bar{p}<1, \bar{\gamma}<1$ such that $\left.V_{\rho}^{\prime}\right|_{\mu^{*}}=0$. Apply the implicit function theorem to obtain:

$$
\Upsilon_{k}^{\prime}=-\frac{V_{\rho k}^{\prime \prime}}{V_{\rho \rho}^{\prime \prime}}=-\frac{w}{V_{\rho \rho}^{\prime \prime}}\left\{\phi_{k}^{\prime}\left[-\frac{\delta(1-L)}{1-\rho}+\frac{w(\delta-1) l_{c}^{\prime}}{2 \delta+\Omega}\right]+\alpha_{k}^{\prime}\left[\frac{w(\delta-1) l_{c}^{\prime}}{2 \delta+\Omega}-\frac{\left(l_{0}-L\right)}{1-\rho}\right]\right\}, \quad k=p, \gamma
$$

It readily follows that:

$$
\Upsilon_{k}^{\prime}<0 \text { if } \alpha_{k}^{\prime}>\phi_{k}^{\prime} \Theta \quad \text { where } \Theta=\frac{-\delta(1-L)(2 \delta+\Omega)+(1-\rho) w(\delta-1) l_{c}^{\prime}}{-\left(l_{0}-L\right)(2 \delta+\Omega)+(1-\rho) w(\delta-1) l_{c}^{\prime}}<0
$$

which proves Proposition 2.

\section{Appendix B Data Appendix}

The dataset draws mainly on (i) The World Bank Database of Political Institutions (DPI) (Beck et al. [15]) and (ii) the OECD Labour Market Institutions Database (LMID), see Bassanini and Duval [14]). Since the information drawn from LMID stops in 2003, we updated the relevant time series to 2006 using original OECD data sources. 


\section{Appendix B.1 Political variables}

The political variables are drawn from the World Bank DPI (Beck et al. [15]). To construct the political indicators used in the empirical analysis, we performed a principal component analysis on different sets of variables. The variable Polturn conveys the idea that adoption of a proportional electoral system, closed lists, election of minimal-winning (or even minority) governments, and a high incidence of veto power groups in parliament are more likely to be associated with a higher propensity for a government change (i.e. political turnover). The following variables were used in the principal component analysis (capital letters denote the original variables in the DPI. See Beck et al. [15] for more details):

$\boldsymbol{P r}$ : dummy equal to 1 if a system of proportional representation is adopted (HOUSESYS= $0)$.

Propmaj: dummy equal to 1 if a mixed plurality and proportional system is adopted but the majority of seats in the House and the Senate are proportional (HOUSESYS $=0$ and $S E N S Y S=0)$.

$\boldsymbol{C L}$ : dummy equal to 1 if closed lists are used.

Nowtal: dummy equal to 1 if a winner-takes-all system is not adopted (PLURALITY=0). Invmaj: inverse margin of majority of the executive over the opposition in parliament $(1 / M A J)$.

$\boldsymbol{S T A B S}$ : percentage of veto players who drop the government in a given year.

Applying principal component analysis to these variables and extracting the score of the first component, that is, the eigenvector associated with the first eigenvalue (i.e. $43 \%$ of the total variance is explained by the first component), leads to the following index of political turnover:

Polturn $=0.55 * \operatorname{Pr}+0.54 *$ Propmaj $+0.39 * C L+0.48 *$ Nowtal $+0.12 *$ Invmaj $+0.04 * S T A B S$,

The variable Polpolar captures the idea that a large ideological distance between majority and opposition and giving a voice to minority ideological and possibly extremist positions, may increase political unrest and polarization in parliament. The variables used in the principal component analysis are:

Maxpolar: dummy equal to 1 if there is maximum ideological distance between the exec- 
utive party and the four main parties in the legislature $(P O L A R I Z=2)$

Godisp, Opdisp: reciprocal of the Herfindal index of government and opposition, that is, the inverse of the sum of the squared seat shares of all the parties in government and the opposition, respectively (1/HERFGOV, 1/HERFOPP).

GOVFRAC, OPPFRAC: probability that two deputies picked at random from among the parties in parliament will be from different parties in the government and opposition, respectively.

The score drawn out of the first component (i.e. accounting for $57 \%$ of the total variance) leads to the following index of political polarization:

Polpolar $=0.22 *$ Maxpolar $+0.52 *$ Godisp $+0.46 * O p d i s p+0.51 * G O V F R A C+0.45 * O P F R A C$,

Consistent with our theoretical expectations, all variables enter with a positive sign in (B-23) and (B-23) that is, all single variables are associated with greater political instability. Both variables were rescaled to have zero mean and unit standard deviation:

$$
X_{s t d}=\frac{X-\bar{X}}{\sigma_{X}}
$$

where $\bar{X}$ and $\sigma_{X}$ are respectively the average and standard deviation of the variable $X=$ Polturn, Polpolar over the sample including the 21 OECD countries for the period 19752006. Note that the length of sample period used for the normalization is motivated by the use of lagged variables throughout the analysis and ensures the unit of measure used for the political variables is fully consistent with the institutional variables (see below).

Ydem: categorical variable for the youth of the democratic institutions. Equal to 3 if the democracy has been in place for less than 20 years $(T E N S Y S<20)$; equal to 2 if the democracy has been in place for 20-40 years $(20 \leq$ TENSYS $<40)$; equal to 1 if the democracy has been in place for more than 40 years (TENSYS $\geq 40$ ).

Prtyage: categorical variable for the age of the parties in parliament, equal to 1 if $P A R T Y A G E<$ 20; equal to 2 if $20 \leq P A R T Y A G E<40$; equal to 3 if $P A R T Y A G E \geq 40$.

Yrcurnt, Yrsoffc: respectively years remaining of the current legislature and years of office of the current government. 
Civil, Common: dummy variable that takes the value 1 if the origin of the legal system is Civil law and 0 otherwise, and a dummy variable that takes the value 1 if the origin of the legal system is Common law and 0 otherwise. Definitions are based on Botero et al. [18].

\section{Appendix B.2 Labour market institutions and economic variables}

The synthetic indicator of labour market regulation $(\mathrm{Lmr})$ is derived from the following indicators for regulation in the area of employment and collective relations law:

Eplr: 1-5 summary indicator of the stringency of employment protection legislation of regular workers (Sources: LMID; OECD Employment Outlook, 2004 and 2009).

LackCorp: indicator for lack of corporatism in the wage bargaining process, which takes the value 1 for high levels of corporatism, 2 for intermediate levels and 3 for low level of corporatism (LMID, OECD Employment Outlook, 2004 and 2009).

Undens: Trade union density rate, that is, share of workers affiliated to a trade union in \% (Sources: LMID; OECD Employment Outlook, 2004 and 2009).

Ltax: Marginal effective tax rate on labor Carey and Rabesona [21] (Sources: LMID; OECD National Accounts and the OECD Revenue Statistics).

Arr: Average unemployment benefits replacement rate which accounts for the replacement rate during the first year of unemployment, and the duration of the monetary transfers aggregated over family types (Sources: LMID; OECD Benefits and Wages Database, 2007). $\boldsymbol{E} \boldsymbol{U}, \boldsymbol{E u r o : ~ D u m m i e s ~ e q u a l ~ t o ~} 1$ if a country is a member of the European Union and the European Monetary Union, respectively.

Crisis: Dummy equal to 1 if effective output falls 4 standard deviations below its potential level.

Additional controls used in the analysis include standardized unemployment rate (number of unemployed persons as a percentage of the civilian labour force for all countries except Austria where we use the commonly used definition; Sources: LMID; OECD Main Economic Indicators); the current deficit (cyclically adjusted current disbursement - cyclically adjustment current receipts of the general government; sources: LMID; OECD National Accounts 2010); the output gap (percentage deviation of effective output from its potential level; sources: LMID; OECD Economic Outlook, 2009); the real effective exchange rate (Source: OECD, Main Economic Indicators) and economic shocks to total factor productivity, terms of trade, real interest rate and labour demand (Source: LMID). 